OPEN ACCESS

Edited by:

Maw Pin Tan

University of Malaya, Malaysia

Reviewed by:

Antony Bayer,

Cardiff University, United Kingdom

Giuseppe Bellelli,

University of Milano-Bicocca, Italy

*Correspondence:

Gregory Y. H. Lip

Gregory.Lip@liverpool.ac.uk

Specialty section:

This article was submitted to Geriatric Medicine

a section of the journal

Frontiers in Medicine

Received: 31 May 2019

Accepted: 19 July 2019

Published: 08 August 2019

Citation:

Zathar Z, Karunatilleke A, Fawzy AM and Lip GYH (2019) Atrial Fibrillation in

Older People: Concepts and

Controversies. Front. Med. 6:175.

doi: 10.3389/fmed.2019.00175

\section{Atrial Fibrillation in Older People: Concepts and Controversies}

\author{
Zafraan Zathar ${ }^{1}$, Anne Karunatilleke ${ }^{1}$, Ameenathul M. Fawzy ${ }^{1}$ and Gregory Y. H. Lip ${ }^{2,3 *}$ \\ ${ }^{1}$ Institute of Applied Health Research, University of Birmingham, Birmingham, United Kingdom, ${ }^{2}$ Liverpool Centre for \\ Cardiovascular Science, University of Liverpool and Liverpool Heart and Chest Hospital, Liverpool, United Kingdom, \\ ${ }^{3}$ Aalborg Thrombosis Research Unit, Department of Clinical Medicine, Aalborg University, Aalborg, Denmark
}

Atrial fibrillation (AF) is the commonest cardiac rhythm abnormality and has a significant disease burden. Amongst its devastating complications is stroke, the risk of which increases with age. The stroke risk in an older person with AF is therefore tremendous, and oral-anticoagulation (OAC) therapy is central to minimizing this risk. The presence of age-associated factors such as frailty and multi-morbidities add complexity to OAC prescription decisions in older patients and often, OAC is needlessly withheld from them despite a lack of evidence to support this practice. Generally, this is driven by an over-estimation of the bleeding risk. This review article provides an overview of the concepts and controversies in managing AF in older people, with respect to the existing evidence and current practice. A literature search was conducted on Pubmed and Cochrane using keywords, and relevant articles published by the 1st of May 2019 were included. The article will shed light on common misconceptions that appear to serve as rationale for precluding $\mathrm{OAC}$ and focus on clinical considerations that may aid OAC prescription decisions where appropriate, to optimize AF management using an integrated, multi-disciplinary care approach. This is crucial for all patients, particularly older individuals who are most vulnerable to the deleterious consequences of this condition.

Keywords: atrial fibrillation, older people, elderly, management, oral anti-coagulation, stroke, frailty, cognitive impairment

\section{INTRODUCTION}

Atrial fibrillation (AF) is the commonest cardiac rhythm disturbance affecting the general population. In 2010, the number of individuals with AF in the European Union over the age of 55 years was estimated to be 8.8 million but this is expected to double to 17.9 million by 2060, with a further 6-12 million likely to be affected in the United States (US) $(1,2)$. It is a significant public health burden estimated to cost the UK National Health Service (NHS) and US healthcare $£ 459$ million and up to $\$ 26$ billion, respectively $(3,4)$.

Although asymptomatic in the vast majority of patients, AF can manifest as ischaemic strokes, leading to hospitalisations, and death. Indeed, AF is associated with a 5-fold increase in the stroke risk (5). Its prevalence in the general population increases steadily with advancing age, from 0.12 $0.16 \%$ in people younger than 49 years to $3.7-4.2 \%$ in those aged $60-70$ years. Beyond the age of 80 years, prevalence can be as high as $10-17 \%(6)$. 
As age is an independent risk factor for AF, the global burden of this condition is expected to increase with the aging population. However, management and treatment of this common arrhythmia in older people has proven to be a dilemma for many, as they are a heterogeneous group of individuals complicated by the presence of functional, and social factors that contribute to their vulnerability, in addition to multimorbidity and polypharmacy; all of which need to be taken into account. It is also partially attributable to the lack of guidelines specific to this patient population.

We aim to provide an overview of the concepts and controversies in managing $\mathrm{AF}$ in older individuals, with respect to current practice, and existing evidence. A literature search was conducted on Pubmed and Cochrane databases using the keywords "atrial fibrillation," "oral anti-coagulation," "management," "older," "elderly," "falls" "frailty," and "cognitive impairment." Relevant articles published by the 1st of May 2019 were included. Randomized controlled trials (RCTs), systematic reviews and meta-analyses are presented as they provide a higher quality of evidence. Other studies including registry studies and observational studies are also included, as they make-up a significant proportion of the evidence base for this population, given the lack of large-scale RCTs, and provide a more "realworld" perspective on oral anti-coagulation (OAC) use in older patients. When selecting relevant papers, the overall study design, and corresponding results were taken into consideration.

\section{AGING AND ATRIAL FIBRILLATION}

The relationship between AF and age has been well-described in the literature and epidemiological studies have been instrumental in establishing this link. Indeed, advancing age is the most prominent risk factor for AF. In the Framingham cohort study which followed individuals over a 22 year period, the incidence of AF was noted to increase with advancing age. Age, along with hypertension, congestive heart failure, diabetes mellitus, coronary artery disease, and valvular disease were identified as independent risk factors for the development of $\operatorname{AF}(7,8)$. This was followed by further studies confirming the link between age and AF, which is now well-established (9-14).

Age is also an independent risk factor for stroke (15). This was signified in the landmark Atrial Fibrillation Investigators (AFI) schema which identified age as a predictor of stroke in AF patients (16). The Stroke Prevention in AF (SPAF) study also recognized its pertinence, noting that females over 75 years had a higher rate of thromboembolic events (17). The age-associated increase in the risk of stroke is not specific to sex and is observed both in males and females (18-21). In the Framingham study, stroke risk increased significantly from 1.5 to $23.5 \%$ at $50-59$ years, and 80-89 years respectively, and in the latter age group, $\mathrm{AF}$ was the sole cardiovascular condition to exert an independent effect on stroke incidence (10).

Age is not a static but a dynamic risk factor for AF-related stroke, and risk increases from 65 years and upwards in Western populations (22). It is a continuous variable, making it difficult to establish an arbitrary cut-off for risk stratification purposes.
TABLE 1 | Stroke risk stratification: $\mathrm{CHA}_{2} \mathrm{DS}_{2}$-VASc score.

\begin{tabular}{lr}
\hline Risk factor & Sco \\
\hline Congestive heart failure & 1 \\
Hypertension & 1 \\
Age $\geq 75$ years & 2 \\
Diabetes mellitus & 1 \\
Stroke/TIA & 2 \\
Vascular disease (prior MI,PAD or aortic plaque) & 1 \\
Age 65-74 years & 1 \\
Sex category: Female & 1
\end{tabular}

The $\mathrm{CHA}_{2} D S_{2}$-VASc score calculates stroke risk in atrial fibrillation. Score of $\mathrm{O}$ is "low risk" may not require anticoagulation. Score of 1 in males and $\geq 2$ in females is "low-moderate" risk and anti-coagulation may be considered as per ESC guidelines. A score of $\geq 2$ and $\geq 3$ in males and females respectively, is "moderate-high" risk and anticoagulation is indicated. Maximum possible score = 9; TIA-transient ischemic attack; MI-myocardial infarction; $P A D$-peripheral arterial disease.

Table 1 outlines the current version of the $\mathrm{CHA}_{2} \mathrm{DS}_{2}$-VASc risk stratification tool which is most widely used in clinical practice.

\section{PATHOPHYSIOLOGY OF AF IN OLDER INDIVIDUALS}

The numerous risk factors that increase the propensity for AF can be grouped into modifiable or non-modifiable risk factors (23). Modifiable risk factors include body mass index (BMI), diabetes, obstructive sleep apnoea (OSA) and hypertension whereas the non-modifiable risk factors include genetics, gender, ethnicity, and of course, age (24). These increase susceptibility to AF by inducing structural and histopathological changes.

The onset of $\mathrm{AF}$ requires both an initiating trigger and an anatomical substrate; in this case, a critical mass of abnormal tissue that can provoke atrial ectopic beats and give rise to paroxysms of AF. The pulmonary veins (PVs) may be the main origin for ectopic triggering foci $(25,26)$. Nevertheless, the exact pathophysiological mechanisms linking age and AF are poorly understood. In older patients, the presence of multiple comorbidities adds to the complexity of establishing the impact of aging vs. the impact of comorbidities on the development of AF, in isolation. The aging heart offers an ideal environment for AF to flourish in the presence of predisposing "anatomical substrate" abnormalities, due to conditions such as hypertension, ischaemic heart disease, heart failure, valvular disease, and dilated/hypertrophic cardiomyopathy (27, 28). These have been associated with histopathological and atrial chamber abnormalities which result in myocardial fibrosis and atrial dilation, thus increasing the risk of AF (29). In addition, the stretching of the atrial fibers due to atrial enlargement leads to a shorter refractory period and slower electrical conduction, further optimizing the conditions for arrhythmogenicity (27).

Over time, repeated episodes of AF lead to further substrate abnormality through structural and electrophysiological remodeling, and modify the cell to cell conduction, resulting in a reduced threshold for AF triggers and conditions which 
sustain AF (30). AF therefore gives rise to additional risk factors which contribute to its own progression; hence, "AF begets AF," explaining how paroxysmal episodes progress into permanent sustained episodes over a period of time. The longer the treatment is delayed, the more difficult it is to regain sinus rhythm (27).

\section{ANTICOAGULATION IN OLDER PEOPLE}

Stroke risk is not homogeneous and risk factors have been used to formulate various stroke (and bleeding) risk stratification schemes (31). Risk is not a static "one off” process but is dynamic in nature, and the change in risk profile leads to an increased risk for outcomes $(32,33)$.

Both the European Society of Cardiology (ESC) and National Institute for Health and Care Excellence (NICE) guidelines (UK) recommend assessment of stroke risk using the $\mathrm{CHA}_{2} \mathrm{DS}_{2}$-VASc score with view to considering $\mathrm{OAC}$ for scores of $\geq 1$ in males and $\geq 2$ in females $(34,35)$. OAC with a vitamin $\mathrm{K}$ antagonist (VKA) or the newer non-vitamin $\mathrm{K}$ antagonist oral anti-coagulants (NOACs) must be recommended for those who meet the criteria. The guidelines are in agreement that OACs are superior to aspirin and aspirin monotherapy should not be offered to patients with AF, solely for stroke prevention. The American College of Cardiology/American Heart Association/Heart Rhythm Society (ACC/AHA/HRS) guidelines differ slightly with OAC being recommended for higher $\mathrm{CHA}_{2} \mathrm{DS}_{2}$-VASc scores of $\geq 2$ and $\geq 3$ in men and women, respectively. For scores of 1 , management options include withholding OAC, or treatment either with an OAC or aspirin (36).

Given that the default is to offer stroke prevention unless patients are "low risk," the recommendations have shifted to initially identify low risk patients first (rather than high risk ones) who do not need any antithrombotic therapy (37). The next step is to offer stroke prevention to those with $\geq 1$ additional stroke risk factors (38).

\section{Perceptions Regarding Oral Anti-coagulation}

As previously established, both age and AF are independent risk factors for stroke, meaning that the older patient with $\mathrm{AF}$ is particularly vulnerable to developing a stroke (15). The metaanalysis by Albertsen et al. (39) showed that older patients are more likely to have a stroke even when on an OAC, despite a $64 \%$ stroke risk reduction with warfarin (40). Indeed, this suggests that there is greater benefit to be derived from OACs by those who are older. Despite this, OAC underuse remains a pressing issue in the older patient population (41).

Pugh et al. (42) in a systematic review explored physicians' attitudes toward OAC for stroke prevention in older people. Barriers to OAC prescription in order of most cited reasons included bleeding risk, falls risk, age, and patients' ability to comply with the treatment regimen. The study also reported that even in the absence of any contraindications to warfarin, physicians were still unlikely to recommend OAC for patients over 70 compared to those $\leq 70$ years of age. In another review, limited evidence or perceived uncertainty, the need for individualized decision making and feelings of delegated responsibility were identified as key physician concerns which deterred them from prescribing OAC (43).

These reservations by clinicians are partially justified by the limited evidence specific to this cohort. Few RCTs specific to older people have been carried out and even then, older patients are under-represented in the existing RCTs. In most cases, results from such studies are extended to these patients and their direct applicability to the older individual is frequently questioned.

In addition, the $\mathrm{CHA}_{2} \mathrm{DS}_{2}$-VASc score which is largely driven by age is poorly helpful in determining the therapeutic approach in older individuals. This is particularly true for those over 75 years, for whom OAC therapy is indicated by definition, regardless of the presence of other factors. In essence, this makes the tool almost unnecessary in cardio-geriatric practice and what would be more helpful is a decision-making guide that incorporates factors such as frailty, and comorbidities such as dementia which influence treatment decisions in this age group. This is also true for the bleeding risk scoring systems, most of which incorporate age, and stroke. Thus, the overlap in these components of the risk stratification scores result in a parallel increase in the stroke and bleeding risks that is less helpful and to a certain extent, these scores almost seem like an oxymoron.

Indeed, risk stratification scores serve as tools to guide treatment decisions and must not be used as replacements for existing evidence and/or clinical judgement, i.e., bleeding risk scores should be used to identify patients who are at a higher risk of bleeding, to initiate closer monitoring strategies as advocated by the guidelines $(34,36)$. Yet, they are often used to justify withholding OAC therapy from patients who have an equal or higher risk of stroke (44). In their study, Friberg et al. (45), demonstrated that the risk of ischaemic stroke without OAC was higher than the risk of bleeding with OAC, unless the risk of ischaemic stroke was very low $\left(\mathrm{CHA}_{2} \mathrm{DS}_{2}\right.$-VASc $\left.=0\right)$. For a patient with a $\mathrm{CHA}_{2} \mathrm{DS}_{2}$-VASc and HAS-BLED (comprising of hypertension, renal impairment, liver dysfunction, stroke history, prior major bleeding, or predisposition to bleeding, labile INR, age $>65$ years, medications predisposing to bleeding and drug/alcohol use) score of 5, the net clinical benefit (NCB) of OAC was still $3 \%$ per year, even with a weight of 1.5 applied to intra-cranial hemorrhage (ICH) events, to account for their disastrous consequences.

Nonetheless, decision-making aids that are more specific to older people, inclusive of age-associated factors, may help minimize some of the physician concerns and uncertainties toward prescribing $\mathrm{OAC}$.

\section{Conventional Oral Anticoagulants}

In the general population, it is well-established that warfarin is superior to both mono and dual anti-platelet therapy. In a systematic review and network meta-analysis, López-López et al. (46) demonstrated that aspirin $<150 \mathrm{mg}$ once daily [OR 1.88 (1.40 to 2.51$)$ ] and aspirin $\geq 150 \mathrm{mg}$ once daily [OR 1.61 (1.25 to 2.07)] were both inferior to warfarin (INR 23) for prevention of stroke and systemic embolism in patients with AF. Major bleeding in patients receiving warfarin was 
TABLE 2 | Secondary analyses studies of the phase III trials of NOACs vs. warfarin.

\begin{tabular}{|c|c|c|c|c|c|}
\hline Study & Population & Older patients $\%$ & Intervention & Stroke \& SE (95\% Cl) & Major bleeding (95\% Cl) \\
\hline RE-LY (55) & 18,113 & $\begin{array}{l}<75 \text { years: } 59.9 \\
75-79 \text { years: } 23.4 \\
\text { 80-84 years: } 12.7 \\
\text { ?85 years: } 4.0\end{array}$ & $\begin{array}{l}\text { Dabigatran } 110 \mathrm{mg} \\
\text { b.i.d } \\
\text { Dabigatran } \\
150 \mathrm{mg} \text { b.i.d }\end{array}$ & 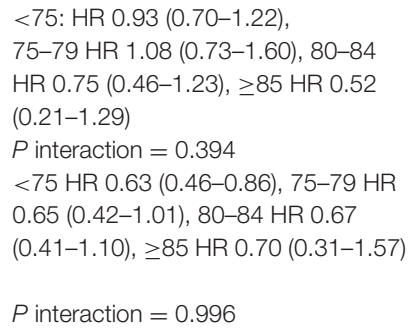 & $\begin{array}{l}<75 \text { HR } 0.62(0.50-0.77), \\
75-79 \text { HR } 0.93(0.71-1.21), \\
80-84 \text { HR } 1.18(0.84-1.65), \geq 85 \mathrm{HR} \\
1.01(0.59-1.73) \\
P \text { interaction }=0.006 \\
<75 \text { HR } 0.70(0.57-0.86), 75-79 \mathrm{HR} \\
1.04(0.81-1.35), 80-84 \mathrm{HR} 1.41 \\
(1.02-1.94), \geq 85 \mathrm{HR} 1.22(0.74-2.02) \\
\boldsymbol{P} \text { interaction }=\mathbf{0 . 0 0 1}\end{array}$ \\
\hline ROCKET AF (56) & 14,264 & $\geqslant 75$ years: 43.7 & $\begin{array}{l}\text { Rivaroxaban } 20 \text { mg } \\
\text { daily }\end{array}$ & $\begin{array}{l}<75 \text { HR } 0.95(0.76-1.19) \\
\geq 75 \text { HR } 0.80(0.63-1.02) \\
P \text { interaction } P=0.313\end{array}$ & $\begin{array}{l}<75 \text { HR } 0.96(0.78-1.19) \\
\geq 75 \text { HR } 1.11(0.92-1.34) \\
P \text { interaction } P=0.336\end{array}$ \\
\hline ARISTOTLE (57) & 18,201 & $\begin{array}{l}<65 \text { years: } 30.1 \\
65-74 \text { years: } 38.7 \\
\geqslant 75 \text { years: } 31.2\end{array}$ & Apixaban 5 b.i.d & $\begin{array}{l}<65 \text { HR1.16 (0.77-1.73), } \\
65-74 \text { HR } 0.72(0.54-0.96) \\
\geqslant 75 \text { HR } 71(0.53-0.95) \\
P \text { interaction }=0.11\end{array}$ & $\begin{array}{l}<65 \text { HR } 0.78(0.55-1.11), 65-74 \mathrm{HR} \\
0.71(0.56-0.89) \\
\geqslant 750.64(0.52-0.79) \\
P \text { interaction }=0.63\end{array}$ \\
\hline $\begin{array}{l}\text { ENGAGE AF-TIMI } \\
48(58)\end{array}$ & 21,105 & $\begin{array}{l}<65 \text { years: } 26.0 \\
65-74 \text { years: } 33.8 \\
\geqslant 75 \text { years: } 40.2\end{array}$ & Edoxaban 60 mg daily & $\begin{array}{l}<65 \mathrm{HR} 0.94(0.65-1.37), 65-74 \mathrm{HR} \\
0.89(0.68-1.16), \geqslant 75 \mathrm{HR} 0.83 \\
(0.66-1.04) . \\
P \text { interaction }=0.84\end{array}$ & $\begin{array}{l}<65 \mathrm{HR} 0.81(0.58-1.12), 65-74 \mathrm{HR} \\
0.75(0.60-0.94), \geqslant 75 \mathrm{HR} 0.83 \\
(0.7-0.99) . \\
P \text { interaction }=0.78\end{array}$ \\
\hline
\end{tabular}

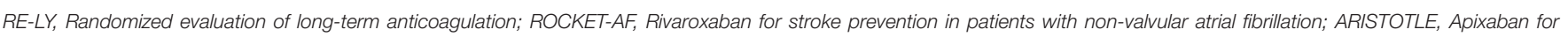

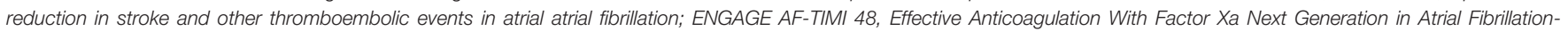

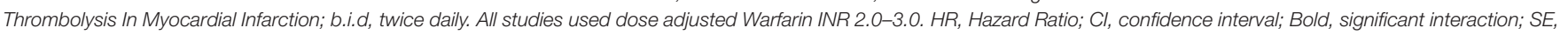
systemic embolism.

comparable to patients on anti-platelets. Of the RCTs included in this meta-analysis only 3 trials [AF-ASA-VKACHINA (47), BAFTA (48), and WASPO (49)] selectively investigated the older population, comparing antiplatelet therapy with warfarin. To date, BAFTA is the largest RCT involving older AF patients. The multi-center RCT randomized 973 patients into doseadjusted warfarin (INR target 2-3) or aspirin $75 \mathrm{mg}$ daily treatment arms. The warfarin group had fewer numbers of strokes [OR $0.52,95 \%$ CI $(0.33-0.80)]$ and the same number of major hemorrhages $[0.96,95 \%$ CI $(0.53-1.75)]$ compared to the aspirin group.

In a more recent meta-regression analysis, Bai et al. (50) identified six studies $(47-49,51-53)$ that specifically looked at warfarin vs. aspirin in the older population (defined as age $\geq 65$ years old). Unsurprisingly, warfarin was superior to aspirin for the prevention of stroke/thromboembolism [RR $0.44,95 \%$ CI $(0.24-0.64)]$ with no significant increase in major bleeding (RR 1.20, 95\%CI [0.91-1.50]). With advancing age, the RR for stroke/thromboembolism for warfarin vs. aspirin was attenuated $\left(r^{2}=0.76, P=0.002\right)$ but no significant reductions were observed in the $\mathrm{RR}$ for major bleeding $\left(r^{2}=0.20, P=0.22\right)$.

\section{Newer Oral Anticoagulants}

The NOACs, also referred to as direct oral anticoagulants (DOACs), provide an alternative to warfarin for thromboprophylaxis. They may be more favorable in the older person, given that they do not require routine monitoring, have a wider therapeutic window and have fewer food and drug interactions unlike warfarin (54).
The efficacy and safety of NOACs have been demonstrated in large RCTs comparing these drugs (i.e. dabigatran, rivaroxaban, apixaban and edoxaban) to warfarin (55-58). These are supported by numerous "real world" studies which have also demonstrated these findings. $(33,59)$. However, in these RCTs, older patients were under-represented with less than half of the study populations comprising of participants $\geq 75$ years of age. Subsequent analyses of the data from these trials (Table 2) demonstrated that NOACs were non-inferior to dose adjusted warfarin for the prevention of stroke and systemic emboli even in the older cohorts (60-63). Despite this, an issue consistently raised by clinicians with respect to these trials is that they are not truly reflective of real-world practice. Study participants are not regarded as accurate depictions of real-world patients, as they represent a minority who are uncomplicated and "fit" enough to fulfill stringent study criteria. Further, many of the systematic reviews and meta-analyses comparing warfarin to NOACs are based on RCT data, with few based on real world studies and focused on older people (Table 3). Nonetheless, these results indicate that NOACs are generally preferable to warfarin for prevention of stroke and systemic emboli in patients aged $\geq 75$ years, while the rates of major bleeding are comparable.

Given that every NOAC has its own efficacy and safety profile, comparing them collectively as a group against warfarin would not be just, nor would it provide clinicians with an accurate idea of their benefits and risks with real-world use. Lin et al. (69), in their systematic review and network metaanalysis, have shed some light on this. Their study included both RCTs and non-RCTs to provide a real-world assessment of the NOACs. They compared dabigatran, rivaroxaban, apixaban, 
TABLE 3 | Meta-analysis of NOACs vs. Warfarin for stroke prevention in older individuals with AF.

\begin{tabular}{|c|c|c|c|c|}
\hline References & Study design & Comparison & Stroke/SSE (95\%Cl) & Major hemorrhage $(95 \% \mathrm{Cl})$ \\
\hline Bai et al. (50) & $\begin{array}{l}\mathrm{SR}+\mathrm{MRA} \\
(\mathrm{RCT}=7, \text { cohort }=7, \\
\text { national registry }=1 \\
\text { and observational }=1)\end{array}$ & $\mathrm{NOAC}^{\dagger}$ vs. Warfarin & $\geq 65$ years: HR 0.81 (0.73-0.89) & $\geq 65$ years: HR 0.87 (0.77-0.97) \\
\hline Kim et al. (64) & $\mathrm{SR}+\mathrm{MA}(\mathrm{RCT}=5)$ & $\mathrm{NOAC}^{\dagger}$ vs. Warfarin & $\geq 75$ years: RR 0.83, (0.69-1.00) & equivalent safety ${ }^{*}$ \\
\hline Ruff et al. (65) & $\mathrm{MA}(\mathrm{RCT}=4)$ & $\mathrm{NOAC}^{\dagger}$ vs. Warfarin & $\begin{array}{l}<75 \text { years RR } 0.85(0.73-0.99) \\
\geq 75 \text { years RR } 0.78(0.68-0.88)\end{array}$ & $\begin{array}{l}<75 \text { years } R R 0.79(0.67-0.94) \\
\geq 75 \text { years RR } 0.93(0.74-1.17)\end{array}$ \\
\hline Briceno et al. (66) & $\begin{array}{l}\mathrm{SR}+\mathrm{MA} \\
(\mathrm{RCT}=7)\end{array}$ & NOAC $^{\dagger}$ vs. Warfarin & $\geq 75$ years: OR 0.77 (0.68-0.87) & * \\
\hline Sardar et al. (67) & $\begin{array}{l}\text { MA } \\
(\mathrm{RCT}=10)\end{array}$ & $\begin{array}{l}\mathrm{NOAC}^{\ddagger} \text { vs. conventional } \\
\text { therapy }\end{array}$ & $\geq 75$ years: OR $0.65(0.48-0.87)$ & $\geq 75$ years: OR $1.02(0.73-1.43)$ \\
\hline Lega et al. (68) & $\begin{array}{l}\mathrm{MA} \\
(\mathrm{RCT}=3)\end{array}$ & $\mathrm{NOAC}^{\ddagger}$ vs. Warfarin & $\begin{array}{l}<75 \text { years } R R 0.83(0.71-0.96) \\
\geq 75 \text { years: RR } 0.77(0.67-0.89)\end{array}$ & $\begin{array}{l}<75 \text { years } R R 0.73(0.65-0.81) \\
\geq 75 \text { years } R R 0.90(0.82-1.00)\end{array}$ \\
\hline
\end{tabular}

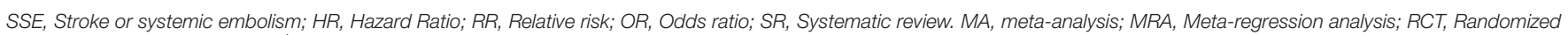

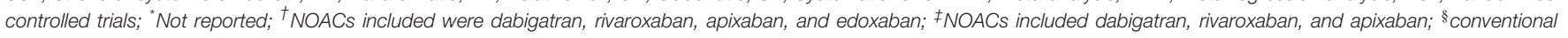
therapy included Vitamin K antagonists, low-molecular weight heparin, aspirin, and placebo.

and edoxaban individually with warfarin for stroke and systemic emboli (SSE) and major hemorrhage. In patients aged $\geq 75$ years, dabigatran $150 \mathrm{mg}$ and apixaban both significantly reduced events of SSE (rate ratio 0.74 and 0.69 respectively, $95 \% \mathrm{CI}<1$ for both), whilst other NOACs showed no significant differences to warfarin. In terms of adverse events, only apixaban was associated with a clinically significant reduction in major bleeding in older people [rate ratio 0.67 (95\% CI 0.55-0.82)]; all other NOACs were similar to warfarin for major bleeding.

\section{BLEEDING RISK}

Like the stroke risk, advancing age is also accompanied with an increased propensity for bleeding and this bleeding risk is a commonly cited reason for OAC underuse and inappropriate cessation $(70,71)$. OAC cessation leads to worse outcomes amongst older people $(72,73)$. Indeed, the HAS-BLED scoring system recognizes age as an independent risk factor for bleeding in anticoagulated patients and a score of $\geq 3$ classifies individuals as "high-risk" (Table 4) (74). However, both the NICE and ESC guidelines recommend using the score to identify and treat reversible risk factors associated with this increased risk rather than denying patients of OAC based on the score alone $(34,35)$.

The risk of major bleeding associated with warfarin has been explored in a number of reviews; but, the studies included have variable definitions of major bleeding with some considering only extra-cranial bleeding events and others including all bleeding events. Current opinion on the major bleeding risk is mixed as some studies report higher risks with warfarin (75-79), whilst others do not report any significant differences $(50,80,81)$.

Nonetheless, all RCTs for NOACs have consistently reported a significantly lower risk of ICH compared to warfarin (55-58). $\mathrm{ICH}$ is one of the most feared complications of OAC, particularly in older individuals and can often be a terminal event in this age group. Chao et al. (82), in a nationwide cohort study looked at the use of OAC in very old patients ( $\geq 90$ years) with AF. They noted that in these nonagenarian, warfarin use was not associated
TABLE 4 | Bleeding risk with oral anti-coagulation: HAS-BLED score.

\begin{tabular}{lc}
\hline Characteristic & Score \\
\hline Uncontrolled Hypertension & 1 \\
Abnormal renal and/or liver function & $1-2$ \\
Stroke history & 1 \\
Bleeding & 1 \\
Labile INR & 1 \\
Age $>65$ years & 1 \\
Drugs and/or alcohol & $1-2$
\end{tabular}

Maximum 9 points. Hypertension defined as systolic $>160 \mathrm{~mm} \mathrm{Hg}$. Renal disease is dialysis, transplant, creatinine $>200 \mu \mathrm{mol} / \mathrm{L}$. Liver disease is cirrhosis or biochemical evidence of liver derangement (bilirubin $>2 x$ normal with AST/ALT/AP $>3 x$ normal). Bleeding is either prior major bleeding or predisposition to bleeding (e.g., bleeding diathesis, anemia). Labile INR [international normalized ratios] is unstable/high INR or a time in therapeutic range (TTR) of $<60 \%$. Drugs refer to medications predisposing to bleeding (e.g., aspirin, clopidogrel, and NSAIDs]. Alcohol is $\geq 8$ drinks/week.

with an increased risk of ICH that was of statistical significance, compared to patients who were not on antithrombotic therapy [HR 1.22 (95\% CI $0.68-2.18), p=0.512$ ]. The study also had a second cohort where comparisons were made between warfarin and NOACs. Although stroke risks were similar, the $\mathrm{ICH}$ risk was markedly lower with NOACs, indicating that the NCB is higher with these drugs. A similar study by Alnsasra et al. (83) demonstrated a positive NCB favoring OAC therapy in patients over the age of 75 years, with the greatest NCB observed in the group aged 75-84 years, those treated with higher doses of DOACs or with a time in therapeutic range (TTR) of $\geq 60 \%$ (if warfarin treated), highlighting the importance of optimal dosing (84).

NOACs in general, have been shown to have satisfactory safety profiles compared to warfarin in those who are older, with some even demonstrating superiority over the VKA in certain domains (Table 3). Despite this, the lack of a uniform and welldefined guidance for clinicians on the selection of an appropriate 
$\mathrm{OAC} / \mathrm{NOAC}$ has resulted in a largely varied practice across the globe, not necessarily dependent on the safety profiles of the drugs. In the initial stages, dabigatran, a drug with a relatively higher risk of overdose and GI bleeding, due to the longer halflife, and predominant renal dependence for clearance, was avidly prescribed. This may have been because dabigatran was the only approved NOAC at one point in time that also had a reversal agent. However, recent evidence has demonstrated declining prescription rates for dabigatran, particularly in older patients $(85,86)$. Increasing awareness, availability of other NOACs and the development of antidotes for these may be amongst the contributing reasons.

Sharma et al. (87) reviewed the safety and efficacy of NOACs in a large systematic review and meta-analysis that included RCT data on NOACs prescribed for both stroke prevention in AF as well as secondary prevention of venous thromboembolism. Compared to VKAs, apixaban, and edoxaban were associated with significant reductions in major hemorrhage [odds ratio [OR] range $0.63-0.81,95 \% \mathrm{CI}<1, p<0.05$ for both] in the population aged $\geq 75$ years. However, both dabigatran $150 \mathrm{mg}$ (OR 1.78, 95\% CI 1.35-2.35), and $110 \mathrm{mg}$ (OR 1.40, 95\% CI 1.04-1.90) increased the risk of GI bleeding in these patients. Regardless, dabigatran $150 \mathrm{mg}$ (OR 0.43, 95\% CI $0.26-0.72$ ), and $110 \mathrm{mg}$ (OR $0.36,95 \%$ CI $0.22-0.61$ ) still had significantly lower risks of ICH when compared to VKAs. These observations have been replicated in a meta-analysis of realworld studies by Romanelli et al. (88) where both dabigatran 150 and $110 \mathrm{mg}$ were associated with a significantly lower risk of ICH compared to warfarin. However, patients aged $\geq 75$ years had an $\sim 50 \%$ higher chance of gastrointestinal bleeding compared to younger patients. The findings warrant caution when prescribing high dose dabigatran for older individuals, who have multiple concomitant risk factors for GI bleeding.

The analysis of phase III trial data also showed that rivaroxaban is non-inferior to warfarin and is not associated with significant major bleeding (Table 2). However, significantly higher rates of the combined end point of major bleeding and clinically relevant non-major bleeding $(P$ interaction $=0.009)$ were observed in older patients taking rivaroxaban. This was thought to be driven primarily by gastrointestinal bleeding. However, analysis of NCB based on prevention of ischaemic stroke, life threatening bleeding and all-cause mortality indicated that the overall benefit of rivaroxaban over warfarin was still higher in the older cohort (60).

In a sub-analysis of the ARISTOTLE trial, apixaban was associated with lower rates of major bleeding (HR 0.66, 95\% CI $0.48-0.90$ ), and ICH (HR 0.36, 95\% CI 0.17-0.77) in patients $\geq 80$ years of age, relative to warfarin. In the AVERROES trial which compared apixaban and aspirin, rates of major bleeding were similar for $\geq 75$ and $\geq 85$ age groups (89). Further, the ENGAGE AF-TIMI 48 trial also suggested a greater NCB with edoxaban with advancing age. The post-hoc analysis demonstrated that the benefits were maintained even in the extremes of age ( $\geq 80$ and $\geq 85$ years) (62). Again, this was primarily thought to be due to the reduction in major bleeding and $\mathrm{ICH}$ associated with edoxaban.
Understandably the decision to initiate OAC in older patients and the choice of anticoagulant, can pose a dilemma for clinicians but often, this can be driven by patients' risk factor profiles and preferences. A study by Devereaux et al. (90) showed that compared to physicians, patients placed more value on avoiding strokes rather than avoiding bleeding. The authors strongly recommended giving importance to what patients considered significant during the decision-making process. Some may favor stroke prevention and accept the bleeding risk whilst others, may choose not to take a medication that may increase their risk of bleeding.

The lack of direct comparisons between the NOACs and the heterogeneity in patient populations between the phase III trials add to the challenge of deriving clear guidelines for NOAC use in older patients. Hence, the choice of NOAC should be based on a comprehensive review of comorbidities such as renal dysfunction and other variables such as cognitive decline, nutrition status, and polypharmacy.

\section{FRAILTY}

Frailty is described as a clinically recognizable state of increased vulnerability due to an age-associated decline in reserve and function across multiple physiological systems, compromising an individual's ability to cope with daily activities or acute stressors (91). The growing understanding of its association with the risk of adverse outcomes such as falls, worsening disability, hospitalisations and mortality has led to a significant focus on this syndrome (92). Frailty is thought to be reflective of an individual's biological age; a more accurate predictor for the occurrence of such adversities compared to chronological age. That said, it is more prevalent in those who are $>65$ years, and females in particular $(93,94)$.

While a quarter to three quarters of people over the age of 85 years is thought to be frail, up to three quarters may also not be frail, suggesting that there are significant variations in the way frailty develops, is assessed, and classed (95). Data on the prevalence of frailty in patients with $\mathrm{AF}$ is limited in the literature, highlighting a lack of research in this field. A recent systematic review of 11 studies by Villani et al. (93) focusing on this very subject, identified a frailty prevalence ranging from 4.4 to $75.4 \%$. Age was regarded as the principle factor for the large variation, given the low prevalence of $4.4 \%$ reported in the study by $\mathrm{Ng}$ et al. (96), where the mean age of the participants was lower at $66.7 \pm 7.8$ years. However, it is worth noting that the majority of the included studies were based on hospitalized in-patients whose general health is likely to have been poorer. In another metaanalysis by Wilkinson et al. (97), frailty prevalence in AF patients varied from about $6 \%$ in a registry of outpatients to about $100 \%$ in a nursing home population. This suggests that the numbers quoted in studies are largely dependent on the study setting and likely overestimated as most are hospital based. Further, the criteria for assessing frailty differed between the studies, preventing direct comparisons. Hence, the true prevalence of frailty in the general AF population is yet to be determined and longitudinal studies where frailty assessment is based on more 
homogeneous criteria are needed (93). Like many factors, frailty status is dynamic and subject to change over time.

There are a variety of tools used in the identification, assessment and gradation of frailty. Broadly speaking, the concept of frailty is based on two main models (Table 5); the phenotype model (Fried's Criteria) and the cumulative deficits model [Frailty Risk Index/Frailty Index (FI)]. Subsequent tools building on these, such as the Rockwood Clinical Frailty Scale, Edmonton Frail Scale, and the Groningen Frailty Indicator have since developed (99-101).

The phenotype model, based on physical and functional indicators, was developed by Fried et al. (102) using data from the Cardiovascular Health Study (CHS), performed on a community-dwelling population. The landmark study identified comorbidity as a risk factor for, and disability as a consequence of frailty, describing an overlap but distinguishing between the three. Five pre-defined criteria which include unintentional weight loss (of more than $10 \mathrm{lbs}$ in the past year), self-reported exhaustion, weakness (assessed by grip strength), slow walking speed and low physical activity are assessed and a point is allocated for each variable if present. A score of $0,1-2$ and 3 represent individuals who are robust, at risk of developing frailty (pre-frail) and frail, respectively. Although this model enables assessment of the frailty status in individuals without the need for a comprehensive clinical assessment, it does not offer any information about the underlying conditions which may be contributing to the presence of these variables. Further, the tasks though simple at first glance, may be challenging to execute in the presence of certain physical and cognitive limitations, and in the absence of equipment such as hand-held dynamometers that are not readily available in the clinical setting.

The cumulative-deficits model in contrast, was developed from the Canadian Study of Health and Aging (CSHA) and assumes that frailty is a result of an accumulation of individual deficits (inclusive of symptoms, signs, abnormal laboratory values, disease classifications, and disabilities) $(103,104)$. A comprehensive geriatric assessment is required and each variable whether a hearing impairment or a diagnosis of atrial fibrillation is presumed to have an equal effect on the frailty status and risk of adverse outcomes. The FI is derived from a mathematical calculation where the number of individual "deficits" possessed by an individual is divided by the total number of variables or deficits measured. For example, if 10 of 20 variables are present, the FI is $10 / 20=0.5$. The number derived may be used as a continuous variable (i.e. the higher the number, the more likely an individual is to be frail and the less their physiological reserve will be, to adapt to stressors and allow accumulation of further deficits) $(103,105)$.

The FI is particularly advantageous in the long-term follow-up of a patient as changes to this number highlight improvements or worsening of the frailty status. This also emphasizes the notion that frailty is gradable rather than being present/absent (105). The FI has also been categorized using pre-defined cut-off points by Rockwood et al. which have varied in studies. In one of their studies, classifications were made as follows: $\leq$ 0.03 -relatively fit, $>0.031-\leq 0.10$-less fit, $>0.10-\leq 0.21$-least fit, $>0.21-\leq 0.45$-frail, and $\geq 0.45-$ most frail and in another, the FI cut-off for frailty was $\geq 0.25(98,106)$. Although the original study involved assessment of 92 different parameters, subsequent research has indicated that this can be reduced to a more feasible number of about 30 , without loss of predictive value (103). Thus, items included in the FI are not fixed and any variable (that fulfills specified criteria) can be incorporated. While this allows flexibility, the lack of a standardized "proforma" and categorisations that translate into classes of risk pose issues in clinical practice as well as research.

Despite the unique features between the phenotype and cumulative deficits models, a significant overlap exists in their ability to predict future adverse health outcomes such as falls and death (107). Their applicability and usefulness however, may depend on the general state of an individual at the time of evaluation. The correct and combined use of both models is therefore recommended as they provide complementary information on the individuals and their risk factor profiles (105). However, the exhaustive nature of the models limits their use as quick and convenient bed-side screening tools that can be used easily by clinicians. Currently, comprehensive geriatric assessments are considered the "gold-standard" for frailty assessment (108).

Frailty is extremely relevant to the older AF population as it is one of the most commonly cited reasons for OAC under-prescription when in fact, frail patients may stand to achieve the most benefit from it $(109,110)$. In a recent systematic review and meta-analysis, Oqab et al. (111) demonstrated that frailty significantly reduced the prescription of OAC (OR 0.49, 95\% CI 0.32-0.74), with cognitive impairment and malnutrition amongst the other commonly cited geriatric reasons. One explanation for this is the association between frailty and falls and the consequent risk of ICH.

According to a meta-analysis by Cheng et al. (112) frail older adults are at a higher risk of having recurrent falls compared to the pre-frail and robust older adults groups. Whilst this may be an irrevocable fact, it is important to consider the individual factors contributing to the individual's frailty status and falls risk. Frailty does not equate to having falls and often, the risk of falls can correspond to potentially reversible factors and be minimized by addressing these. This includes provision of visual and hearing aids for those with sensory impairments, performance of mobility assessments on at-risk patients such as those with gait impediments, provision of mobility aids and balance-improving exercises for patients who require them and adjustments to the general area of living where needed (113).

To further evaluate the OAC-associated bleeding risk in AF patients who were at risk of developing falls, Man-Son-Hing et al. (114) designed a Markov decision analytic model and performed multiple analyses. In the base-case analysis which included older individuals with an average annual stroke risk of $6 \%$ and falls risk of $33 \%$, warfarin was associated with the highest quality-adjusted life expectancy compared to aspirin or no treatment at all. Warfarin remained the superior choice, regardless of the annual risk (from 0 to 100\%) of having a fall. The study also estimated that an older patient taking warfarin would need to fall 295 times a year to offset the benefits of OAC. This suggests that the perceived falls-related ICH risk is higher 
TABLE 5 | Summary of key characteristics of the two frailty models.

\begin{tabular}{|c|c|c|}
\hline Features & Frailty phenotype by Fried et al. & Frailty Index by Rockwood et al. \\
\hline Definition & Described by physical and functional characteristics & An accumulation of deficits related to activities of daily living \\
\hline Criteria & Pre-defined/set criteria (of 5 phenotypic components) & Non-fixed set of variables (of at least $\geq 30$ ) \\
\hline Criteria assessed & $\begin{array}{l}\text { - Unintentional weight loss (of more than } 10 \mathrm{lbs} \text { in the past } \\
\text { - Sear) } \\
\text { - Self-reported exhaustion } \\
\text { - Slowness (assessed by grip strength) } \\
\text { - Low physical activity }\end{array}$ & $\begin{array}{l}\text { Can be developed based on any symptom, sign, abnormal } \\
\text { laboratory value, disease classification, or disability that: } \\
\text { - Is present in at least } 1 \% \text { of the population } \\
\text { - Covers several organ systems } \\
\text { - Has no more than } 5 \% \text { missing data }\end{array}$ \\
\hline Variables & Categorical & Continuous or Categorical \\
\hline Frailty concept & Frailty is present/absent & Frailty is gradable \\
\hline Frailty grading & $\begin{array}{l}\text { 0-Robust } \\
\text { 1-2-Pre-frail } \\
\text { 3-Frail }\end{array}$ & $\begin{array}{l}\text { Continuous: Number between } 0 \text { and } 1 \text {, where the greater the } \\
\text { number, the more frail a person is } \\
\text { Categorical: } \\
\leq 0.03 \text {-Relatively fit } \\
>0.031-\leq 0.10 \text {-Less fit } \\
>0.10-\leq 0.21 \text {-Least fit } \\
>0.21-\leq 0.45 \text {-Frail } \\
\geq 0.45-\text { Most frail }\end{array}$ \\
\hline $\begin{array}{l}\text { Comprehensive } \\
\text { geriatric assessment }\end{array}$ & Not required & Required \\
\hline Cognition & Does not consider cognitive impairment & Considers cognitive impairment \\
\hline Co-morbidities & Does not consider co-morbidities & Considers co-morbidities such as dementia \\
\hline Prognostication & Predictive of adverse outcomes & Predictive of adverse outcomes \\
\hline $\begin{array}{l}\text { Relationship to } \\
\text { disability }\end{array}$ & Disability is seen as a result of frailty. & $\begin{array}{l}\text { No clear distinction between disability and frailty. Disabilities } \\
\text { contribute to frailty. }\end{array}$ \\
\hline Applicability & $\begin{array}{l}\text { Not applicable to patients with disabilities } \\
\text { More suitable for immediate identification of frail/ at } \\
\text { risk individuals }\end{array}$ & $\begin{array}{l}\text { Applicable to patients with disabilities } \\
\text { Can be used in the long-term follow-up of an individual }\end{array}$ \\
\hline Limitations & $\begin{array}{l}\text { Does not include psychosocial components of frailty } \\
\text { Cannot be used on patients with mental/physical limitations } \\
\text { Certain components (e.g., grip strength) are not routinely } \\
\text { done in clinical practice }\end{array}$ & $\begin{array}{l}\text { Time consuming to calculate } \\
\text { Comparison of results between different institutions may not } \\
\text { be possible if different variables are measured/ assessed }\end{array}$ \\
\hline
\end{tabular}

${ }^{\star}$ Cut-off points proposed in study by Song et al. (98).

than the actual risk, owing to an increased, perhaps exaggerated fear surrounding OAC prescriptions in older individuals. The authors proposed that this may be due to the significance of the event which clinicians are more likely to remember, despite the rarity.

Despite a risk of falls, patients can continue to derive benefits from being anticoagulated, the key one being prevention of stroke. Thus, falls or risk of it alone should not be absolute contraindications to OAC (114). In an observational study of hospitalized frail, older patients, those who were nonanticoagulated had significantly more events of ischaemic stroke and clinically relevant bleeding after 1 year follow up, compared to patients who were on OAC. However, no statistical difference was observed in the rates of re-hospitalization, mortality and falls between the anticoagulated, and non-anticoagulated groups (110). The increased bleeding events in the non-anticoagulated group may have been a reflection of their higher baseline bleeding risk that may have led to an aversion from anticoagulation in the first place.

In contrast, Papakonstantinou et al. (115) demonstrated a higher all-cause mortality in non-anticoagulated old, frail patients after 1 year of follow up. Patients discharged without
OAC had higher HEMORR ${ }_{2}$ HAGES (Hepatic or renal disease, Ethanol abuse, Malignancy, Older age, Reduced platelet count or function, Re-bleeding, Hypertension, Anemia, Genetic factors, Excessive fall risk, and Stroke), and clinical frailty scale (CFS) scores and a lower Katz score indicative of an increased bleeding risk, greater degree of frailty, and poorer functional status, respectively. However, the study was small, and although these findings were observed in the group without anticoagulation, it was not clear whether these were the reasons that prevented OAC prescription and if the increased mortality was attributable to AF alone.

Studies looking into OAC prescription rates in frail people have been variable. While practices in countries such as Australia and Mexico have shown that frailty status predicted OAC use in older adults $(109,116)$ there is also evidence to suggest a lack of association between the two $(117,118)$. This is likely a reflection of the variations in practice and guideline recommendations between the regions as well as the perception of frailty by those assessing it. A sub-study from the ORBIT-AF registry (119) revealed that patients with cognitive impairment and frailty were both less likely to be prescribed OAC when in fact, they had a higher predicted risk of stroke and observed mortality. Moreover, 
TABLE 6 | Key findings from studies reporting on oral anticoagulation and cognitive impairment in AF.

\begin{tabular}{|c|c|c|c|c|}
\hline References & Design & Population & Age $( \pm S D)$ & Main results \\
\hline Friberg et al. (45) & $\begin{array}{l}\text { Retrospective } \\
\text { cohort }\end{array}$ & 444,106 & $74-81$ & $\begin{array}{l}\text { After propensity score matching, no difference in the } \\
\text { dementia risk was observed between NOACs and VKAs (HR } \\
0.97,95 \% \mathrm{Cl} 0.67-1.40)\end{array}$ \\
\hline $\begin{array}{l}\text { Mongkhon et al. } \\
(134)\end{array}$ & Meta-analysis & 452,878 & $71-81$ & $\begin{array}{l}\text { OAC use reduced dementia risk compared to no OAC use } \\
\text { (RR } 0.79,95 \% \mathrm{Cl} 0.67-0.93 \text { ) A higher percentage of TTR } \\
\text { significantly reduced dementia risk (RR } 0.38,95 \% \mathrm{Cl} \\
0.22-0.64)\end{array}$ \\
\hline Cheng et al. (133) & Meta-analysis & 471,057 & $>63$ & $\begin{array}{l}\text { OACs reduced cognitive impairment in patients with AF (HR } \\
0.71,95 \% \mathrm{Cl} 69-0.74 ; P<0.00001) \\
\text { NOACs were better than warfarin in terms of the protective } \\
\text { effect on cognition (HR } 0.51,95 \% \mathrm{Cl} 0.37-0.71 ; P \\
<0.00001)\end{array}$ \\
\hline Moffitt et al. (136) & Meta-analysis & 18,876 & - & $\begin{array}{l}\text { No definitive evidence of cognitive benefit or harm from } \\
\text { anticoagulation }\end{array}$ \\
\hline Mavaddat (135) & $\mathrm{RCT}$ & 973 & $81.5 \pm 4.3$ & $\begin{array}{l}\text { No evidence that anticoagulation protects against cognitive } \\
\text { decline }\end{array}$ \\
\hline $\begin{array}{l}\text { Madhavan et al. } \\
(119)\end{array}$ & Observational & 2,800 & 71.2 & $\begin{array}{l}\text { OAC with warfarin was associated with an } \sim 22 \% \text { lower risk } \\
\text { of dementia ( } \mathrm{HR} 0.78,95 \% \mathrm{Cl} 0.64-0.97)\end{array}$ \\
\hline Jacobs et al. (137) & $\begin{array}{l}\text { Retrospective } \\
\text { cohort }\end{array}$ & 5,254 & $72.4 \pm 10.9$ & $\begin{array}{l}\text { Compared to warfarin, patients on NOACs were } 43 \% \text { less } \\
\text { likely to develop stroke/TIA/dementia (HR } 0.57,95 \% \mathrm{Cl} \\
0.17-1.97 ; p=0.38)\end{array}$ \\
\hline Bunch et al. (138) & $\begin{array}{l}\text { Retrospective } \\
\text { cohort }\end{array}$ & 10,537 & $69.3 \pm 10.9$ & $\begin{array}{l}\text { Low TTR increased risk of dementia in } \mathrm{AF}(\mathrm{HR}=2.51, P= \\
0.005)\end{array}$ \\
\hline Barber et al. (139) & Observational & 258 & 72 & $\begin{array}{l}\text { Warfarin use compared to aspirin, was associated with } \\
\text { reduced prevalence of dementia ( } 18 \text { vs. } 32 \% P=0.023)\end{array}$ \\
\hline
\end{tabular}

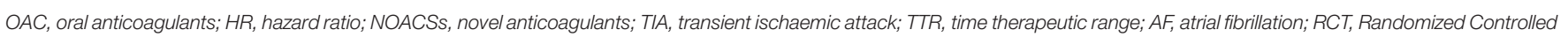
Trial, RR, risk ratio; Cl, confidence interval; VKA, vitamin-K antagonist.

the multivariable analysis demonstrated that there were no interactions between OAC use and frailty, in their associations with mortality, major bleeding, and the composite end point of stroke, systemic embolism, TIA, myocardial infarction, and cardiovascular death.

Nevertheless, the OAC prescription rate of $70 \%$ observed in the FRAIL-AF study (120) compared to rates of $35-65 \%$ seen in historical studies was encouraging, as it suggested a more judicious use of OAC in older patients, particularly as a significant proportion in the study had diagnoses such as dementia. However, the authors noted that nonfrail to moderately frail patients were 3.5 times more likely to receive OAC than severely frail patients, irrespective of their thromboembolic and bleeding risk, highlighting that the impression of severe frailty significantly influenced OAC prescription decisions. This emphasizes an important point, which is the absence of a standard for assessing frailty and its severity, even with the availability of a vast number of frailty assessment tools, as alluded to before. Adjudication of the degree of frailty is thereby left at the physicians' discretion, often influenced by their own knowledge and experience or a lack thereof. For many, the perception of frailty is accompanied by a sentiment of futility towards prescribing OAC; another key issue that underlies $\mathrm{OAC}$ under-prescription and its consequences.

The rising prevalence of frailty necessitates the establishment of a simple and robust frailty assessment tool, applicable to all patients and clinicians. More and more patients with AF are seen outside cardiac settings and similarly, the majority of patients seen in cardiovascular settings comprise older, possibly frail individuals. Hence, the relevance of frailty assessments is no longer limited to geriatricians (or cardiologists) and a validated frailty assessment tool that can be easily utilized for risk stratification is needed to guide decision-making regarding OAC (94). Indeed, presence of frailty should not be the sole determinant and for this reason, having a pre-set cut-off beyond which OAC would not be prescribed may be unwise, as it may lead to an unjustified preclusion of treatment and act as a barrier to an individualized treatment approach. Denying OAC in a frail patient may achieve nothing but a debilitating stroke that adds to their frailty and burden.

ESC guidelines for AF management include a brief section on frail and "elderly" patients which discusses limited available evidence but no recommendations are made with regards to OAC therapy (34). Addressing this with consensus guidelines will undoubtedly benefit patients and physicians.

\section{COGNITIVE IMPAIRMENT}

Several studies have shown an increased incidence of cognitive decline and dementia, including Alzheimer's and vascular dementia, in patients with AF (121-123). Dementia and AF share common cardiovascular risk factors such as heart failure, hypertension, excessive alcohol intake, smoking and diabetes mellitus that could account for this link (124). Regardless, longitudinal studies adjusted for these comorbidities have still shown an association between $\mathrm{AF}$ and cognitive impairment $(121,125)$. 
A number of mechanisms have been proposed, and the most familiar concept is the thromboembolic phenomenon which clinically presents as a stroke, resulting in cerebral infarction. However, cognitive decline has been observed even in the absence of strokes and small vessel disease and/or cerebral microinfarcts have been identified as an underlying cause (126). These "silent" strokes have no clinical manifestation, only apparent on neuroimaging. AF is considered an independent risk factor for cerebral microinfarcts (127).

Another proposed explanation for the link between AF and cognitive impairment is the beat-to-beat variability that occurs in AF, leading to intermittent cerebral hypoperfusion. This in turn results in cerebral ischaemia, particularly in the whitematter regions, and is regarded as a frequent mechanism for cognitive impairment in $\operatorname{AF}(128,129)$. Other inflammatory and neurohormonal processes are also likely contributory (127).

The meta-analysis by Kalantarian et al. (130) highlighted a significant association between AF and dementia, independent of stroke. In the Atherosclerosis Risk in Communities Neurocognitive (ARIC-NCS) study (131) which followed 12,515 patients for over 20 years, incident AF was associated with a $23 \%$ higher risk of dementia, even after adjustments were made for cardio- and cerebrovascular risk factors as well as prevalent and incident ischaemic stroke. The mean age of the participants was $56.9 \pm 5.7$ and although the incidence rates of dementia were significant in those under and over the age of 57 years, it was more pronounced in the $>57$ years group. In contrast, the Rotterdam study (132) which also prospectively followed 6,514 individuals for a similar length of time showed that the risk of dementia was confined only to the younger participants with incident AF, who were $<67$ years. Further, there appeared to be a dose-response relationship as those who had AF for a longer duration were more likely to develop dementia. This is plausible as dementia develops over many years and AF needs to develop at a younger age to contribute to the onset of this condition at a later stage.

The association between AF and dementia has fuelled a vast amount of research to determine if OACs have any therapeutic benefit in attenuating this risk. Given that OACs largely address the thromboembolic complications when taken appropriately, this should theoretically be the case, though cognitive impairment arising from hypoperfusion and related mechanisms would remain unaffected (127). Existing evidence relating to this subject is non-conclusive with some studies demonstrating a reduction in the incidence of dementia with OACs $(133,134)$ and others suggesting otherwise $(135,136)$ (Table 6). The studies where no improvements were observed with OAC were mainly warfarin-based and the quality of anticoagulation control, that is less likely to be achieved with VKAs such as warfarin may explain this observation. Cheng et al. (133) in a meta-analysis recognized that TTR appeared to play an important role in cognitive benefit as TTR $<25 \%$ significantly increased risk of dementia compared to TTR $\geq 75 \%$ (HR 3.02, 95\% CI 1.12-8.91; $P=0.03$ ). Non-adherence, polypharmacy, comorbidities, and drug interactions can all have an impact on TTR in older people but are less likely to influence the quality of anticoagulation with NOACs.
Recent evidence suggests that NOACs may be preferable for reducing incidence of dementia (137). They may also improve adherence as they can be given as once or twice daily regimens without the need for frequent follow-up and can easily be incorporated into multi-drug regimens as well as blister packs and dosette boxes, in patients with cognitive impairment. However, opinions are mixed on whether NOACs or VKAs are better for adherence, in the context of cognitive impairment $(140,141)$. Persistence with therapy is also a challenge, and efforts to improve persistence and adherence are needed $(142,143)$.

On balance OACs, particularly NOACs, appear to be beneficial for reducing the risk of dementia, owing to the reduction in silent cerebral ischaemia or microemboli. However, well-designed RCTs adjusting for confounders, with a longer duration of follow up are awaited to fully explore the impact of OAC on cognitive function (144).

Despite the established benefits of OAC, cognitive impairment remains another reported reason precluding OAC use, over fears of a drug overdose or falls which can result in a bleed. Most individuals with cognitive impairment have their medications administered and are under substantial supervision either by their family members at home or carers in long-term care facilities. In such cases, the likelihood of overdosing on an OAC or incurring harm due to an environmental hazard is low and withholding OAC would only increase the chances of developing a stroke which can cause a greater disability. Of course, there are always more complex cases and in such situations, it may be prudent to have multi-discliplinary discussions to determine the best course of action.

The risk of falls and dementia are addressed in current ESC guidelines which advise withholding OAC only in patients who are likely to have severe uncontrollable falls (e.g., epilepsy) or in selected patients with dementia where caregivers cannot ensure compliance and treatment adherence (34).

\section{RATE vS. RHYTHM CONTROL IN OLDER PEOPLE}

Current NICE guidelines in the UK, recommend that clinicians consider rate control as first line except in the following cases: AF has a reversible cause, new-onset AF, heart failure caused by AF, patients with atrial flutter suitable for ablation and cases where rhythm control is more suitable based on clinical judgement (35). The ESC in their guidance suggests that rhythm control may be indicated in patients who remain symptomatic despite adequate rate control therapy. ESC maintains that the evidence for both rhythm control and rate control is fairly balanced but recognize that data regarding modern rhythm control strategies such as catheter ablation, combination therapy, and early treatment is awaited (34). American guidelines are also on par and outline situations where rhythm control strategies may be attempted and this includes a younger, rather than older patient age (36).

Given that AF is an abnormality of cardiac rhythm, it is reasonable to assume that rhythm control is favorable over rate control. However, in a sub-analysis of the AFFIRM (Atrial Fibrillation Follow-up Investigation of Rhythm 
Management) Trial (145) all-cause mortality was significantly lower in the rate controlled group who were between 70 and 80 years old, compared to the respective rhythm control group (HR 0.77, 95\% CI0.63-0.94, $p=0.01$ ). All-cause hospitalization was also lower in this group (HR 0.76, 95\% CI $0.68-0.86 ; P<0.001)$. There were no differences in the incidence of stroke or major bleeding between the two arms.

An ancillary analysis of the REPOSI study (146), a multicenter observational registry, did not demonstrate significant differences in the cardiovascular and all-cause mortality of older patients managed using rate and rhythm control strategies. In the study, the rate control group was older and had higher rates of polypharmacy, heart failure, and diabetes. Conversely, patients on rhythm control were younger with fewer comorbidities and a better cognitive status. $83 \%$ of patients in the study were managed using rate control strategies, indicating that this is the preferred method. This could be because they are viewed as more conservative and less burdensome on older people, and particularly as it makes no difference to the OAC status as its continuation is still recommended due to the high risk of AF recurrence.

Rate control vs. rhythm control strategies for AF continue to be debated in the literature; however there is paucity of data with respect to those who are of an older age. Whilst some studies suggest that rate control strategies are superior in terms of cost-effectiveness (147), others have noted better outcomes and health-related quality of life with rhythm control interventions $(148,149)$. Nonetheless, real world studies indicate that rate control is more favored and the vast majority of older patients are managed this way (41).

\section{CONCLUSION}

AF is a significant global health burden that is more prevalent in older people. Management of this condition in the geriatric population is riddled with clinical dilemmas. They are accompanied by a high thromboembolic risk but also a concomitant high bleeding risk, requiring clinicians to balance the NCB (150). Indeed, these require deliberation to prevent harm to patients but often, clinical situations are complicated

\section{REFERENCES}

1. Miyasaka Y, Barnes ME, Gersh BJ, Cha SS, Bailey KR, Abhayaratna WP, et al. Secular trends in incidence of atrial fibrillation in Olmsted County, Minnesota, 1980 to 2000, and implications on the projections for future prevalence. Circulation. (2006) 114:119-25. doi: 10.1161/CIRCULATIONAHA.105.595140

2. Krijthe BP, Kunst A, Benjamin EJ, Lip GY, Franco OH, Hofman A, et al. Projections on the number of individuals with atrial fibrillation in the European Union, from 2000 to 2060. Eur Hear J. (2013) 34:2746-51. doi: 10.1093/eurheartj/eht280

3. Stewart S, Murphy NF, Walker A, McGuire A, McMurray JJ. Cost of an emerging epidemic: an economic analysis of atrial fibrillation in the UK. Heart. (2004) 90:286-92. doi: 10.1136/hrt.2002.008748

4. Kim MH, Johnston SS, Chu BC, Dalal MR, Schulman KL. Estimation of total incremental health care costs in patients with atrial fibrillation in the United States. Circ Cardiovasc Qual Outcomes. (2011) 4:313-20. doi: 10.1161/CIRCOUTCOMES.110.958165 by the under-estimation of the thromboembolic risk and overestimation of the bleeding risk. Consequently, OACs continue to be under-used in older individuals.

When making decisions regarding OAC, chronological age is of less importance and biological age, indicated by an individual's frailty and functional status as well as factors such as cognitive impairment must be given careful attention. Nevertheless, their presence should not be regarded as absolute contraindications to OAC use. Risk factor modification, identification of barriers to treatment and involvement of patients and their family members are crucial to the initiation of OAC and improvement of treatment adherence. In the absence of contraindications and as allowed by patients' risk factor profiles, clinicians should explore NOACs as an alternative to conventional VKAs, particularly as they have been shown to reduce the risk of ICH.

OAC prescription practice in older individuals largely varies between regions and even from physician to physician within the same locality. While some guidelines are starting to address certain difficulties faced in treating old patients with OAC, further improvements are needed including consensus recommendations, although the challenges to this must be appreciated.

With the aging population and the anticipated rise in AF prevalence, it is imperative that regulatory bodies and clinicians take responsibility to ensure patients with this condition are treated appropriately and holistically. Indeed, there is a move toward a more integrated or holistic approach to AF management that can be summed up as follows: "A" Avoid stroke; "B" Better symptom control with symptom directed decisions on rate or rhythm control; "C" Cardiovascular risk, and comorbidity management, including attention to lifestyle changes (151). Such an integrated approach has been associated with improved outcomes and reduced healthcare costs (152-154).

\section{AUTHOR CONTRIBUTIONS}

$\mathrm{ZZ}, \mathrm{AK}$, and $\mathrm{AF}$ performed the literature search, wrote the manuscript, and constructed the tables. This was supervised by GL who revised and approved the final version of the manuscript.

5. Wolf PA, Abbott RD, Kannel WB. Atrial fibrillation as an independent risk factor for stroke: the framingham study. Stroke. (1991) 22:983-8. doi: 10.1161/01.STR.22.8.983

6. Zoni-Berisso M, Lercari F, Carazza T, Domenicucci S. Epidemiology of atrial fibrillation: European perspective. Clin Epidemiol. (2014) 6:213-20. doi: 10.2147/CLEP.S47385

7. Benjamin EJ, Levy D, Vaziri SM, D'Agostino RB, Belanger AJ, Wolf PA. Independent risk factors for atrial fibrillation in a populationbased cohort. the framingham heart study. JAMA. (1994) 271:840-4. doi: 10.1001/jama.1994.03510350050036

8. Kannel WB, Abbott RD, Savage DD, McNamara PM. Epidemiologic features of chronic atrial fibrillation: the framingham study. N Engl J Med. (1982) 306:1018-22. doi: 10.1056/NEJM198204293061703

9. Petersen P, Godtfredsen J. Atrial fibrillation-a review of course and prognosis. Acta Med Scand. (1984) 216:5-9. doi: 10.1111/j.0954-6820.1984.tb03763.x

10. Wolf PA, Abbott RD, Kannel WB. Atrial fibrillation: a major contributor to stroke in the elderly. the framingham study. Arch 
Intern Med. (1987) 147:1561-4. doi: 10.1001/archinte.1987.003700900 41008

11. Lake FR, Cullen KJ, de Klerk NH, McCall MG, Rosman DL. Atrial fibrillation and mortality in an elderly population. Aust N Z J Med. (1989) 19:321-6. doi: 10.1111/j.1445-5994.1989.tb00271.x

12. Feinberg WM, Blackshear JL, Laupacis A, Kronmal R, Hart RG. Prevalence, age distribution, and gender of patients with atrial fibrillation. analysis and implications. Arch Intern Med. (1995) 155:469-73. doi: 10.1001/archinte. 1995.00430050045005

13. Go AS. The epidemiology of atrial fibrillation in elderly persons: the tip of the iceberg. Am J Geriatr Cardiol. (2005) 14:56-61. doi: 10.1111/j.1076-7460.2005.02278.x

14. Pandit SV, Jalife J. Aging and atrial fibrillation research: where we are and where we should go. Hear Rhythm. (2007) 4:186-7. doi: 10.1016/j.hrthm.2006.11.011

15. Marinigh R, Lip GYH, Fiotti N, Giansante C, Lane DA. Age as a risk factor for stroke in atrial fibrillation patients. J Am Coll Cardiol. (2010) 56:827-37. doi: 10.1016/j.jacc.2010.05.028

16. Risk factors for stroke and efficacy of antithrombotic therapy in atrial fibrillation. Analysis of pooled data from five randomized controlled trials. Arch Intern Med. (1994) 154:1449-57. doi: 10.1001/archinte.154.13.1449

17. Stroke Prevention in Atrial Fibrillation I. Risk factors for thromboembolism during aspirin therapy in patients with atrial fibrillation: the stroke prevention in atrial fibrillation study. J Stroke Cerebrovasc Dis. (1995) 5:14757. doi: 10.1016/S1052-3057(10)80166-1

18. Flegel KM, Hanley J. Risk factors for stroke and other embolic events in patients with nonrheumatic atrial fibrillation. Stroke. (1989) 20:1000-4. doi: 10.1161/01.STR.20.8.1000

19. van Latum JC, Koudstaal PJ, Venables GS, van Gijn J, Kappelle LJ, Algra A. Predictors of major vascular events in patients with a transient ischemic attack or minor ischemic stroke and with nonrheumatic atrial fibrillation. European Atrial Fibrillation Trial (EAFT) study group. Stroke. (1995) 26:801-6. doi: 10.1161/01.STR.26.5.801

20. Yuan Z, Bowlin S, Einstadter D, Cebul RD, Conners AR Jr, Rimm AA. Atrial fibrillation as a risk factor for stroke: a retrospective cohort study of hospitalized medicare beneficiaries. Am J Public Heal. (1998) 88:395-400. doi: 10.2105/AJPH.88.3.395

21. Gage BF, Waterman AD, Shannon W, Boechler M, Rich MW, Radford MJ. Validation of clinical classification schemes for predicting stroke: results from the national registry of atrial fibrillation. JAMA. (2001) 285:2864-70. doi: 10.1001/jama.285.22.2864

22. Lip GY, Nieuwlaat R, Pisters R, Lane DA, Crijns HJ. Refining clinical risk stratification for predicting stroke and thromboembolism in atrial fibrillation using a novel risk factor-based approach: the euro heart survey on atrial fibrillation. Chest. (2010) 137:263-72. doi: 10.1378/chest.09-1584

23. Aronson D, Shalev V, Katz R, Chodick G, Mutlak D. Risk score for prediction of 10-year atrial fibrillation: a community-based study. Thromb Haemost. (2018) 118:1556-63. doi: 10.1055/s-0038-1668522

24. Staerk L, Sherer JA, Ko D, Benjamin EJ, Helm RH. Atrial fibrillation: epidemiology, pathophysiology, and clinical outcomes. Circ Res. (2017) 120:1501-17. doi: 10.1161/CIRCRESAHA.117.309732

25. Haïssaguerre M, Jaïs $P$, Shah DC, Takahashi A, Hocini M, Quiniou G, et al. Spontaneous initiation of atrial fibrillation by ectopic beats originating in the pulmonary veins. N Engl J Med. (1998) 339:659-66. doi: 10.1056/NEJM199809033391003

26. de Bakker JM, Ho SY, Hocini M. Basic and clinical electrophysiology of pulmonary vein ectopy. Cardiovasc Res. (2002) 54:287-94. doi: 10.1016/S0008-6363(01)00532-6

27. Letsas K, Karamichalakis N, Vlachos K, Georgopoulos S, Bakalakos A, Efremidis M, et al. Managing atrial fibrillation in the very elderly patient: challenges and solutions. Vasc Health Risk Manag. (2015) 11:555. doi: 10.2147/VHRM.S83664

28. Steensig K, Olesen $K$, Thim $T$, Nielsen J, Jensen S, Jensen L, et al. Should the presence or extent of coronary artery disease be quantified in the CHA2DS2-VASc score in atrial fibrillation? a report from the western denmark heart registry. Thromb Haemost. (2018) 118:2162-70. doi: $10.1055 / \mathrm{s}-0038-1675401$

29. Burstein B, Nattel S. Atrial fibrosis: mechanisms and clinical relevance in atrial fibrillation. J Am Coll Cardiol. (2008) 51:802-9. doi: $10.1016 /$ j.jacc.2007.09.064
30. Allessie M, Ausma J, Schotten U. Electrical, contractile and structural remodeling during atrial fibrillation. Cardiovasc Res. (2002) 54:230-46. doi: 10.1016/S0008-6363(02)00258-4

31. Borre E, Goode A, Raitz G, Shah B, Lowenstern A, Chatterjee R, et al. Predicting thromboembolic and bleeding event risk in patients with nonvalvular atrial fibrillation: a systematic review. Thromb Haemost. (2018) 118:2171-87. doi: 10.1055/s-0038-1675400

32. Yoon M, Yang P-S, Jang E, Yu H, Kim T-H, Uhm J-S, et al. Dynamic changes of CHA2DS2-VASc score and the risk of ischaemic stroke in asian patients with atrial fibrillation: a nationwide cohort study. Thromb Haemost. (2018) 118:1296-304. doi: 10.1055/s-0038-1651482

33. Chao T-F, Lip G, Lin Y-J, Chang S-L, Lo L-W, Hu Y-F, et al. Incident risk factors and major bleeding in patients with atrial fibrillation treated with oral anticoagulants: a comparison of baseline, follow-up and delta HAS-BLED scores with an approach focused on modifiable bleeding risk factors. Thromb Haemost. (2018) 118:768-77. doi: 10.1055/s-0038-1636534

34. Kirchhof P, Benussi S, Kotecha D, Ahlsson A, Atar D, Casadei B, et al. 2016 ESC guidelines for the management of atrial fibrillation developed in collaboration with EACTS. Eur J Cardio-Thoracic Surg. (2016) 50:e1-88. doi: 10.1093/ejcts/ezw313

35. National Institute for Health and Care Excellence. NICE CG(180) atrial fibrillation (Update): the management of atrial fibrillation. Natl Institute Health Care Excel. (2014).

36. January CT, Wann LS, Alpert JS, Calkins H, Cigarroa JE, Cleveland JC Jr, et al. AHA/ACC/HRS guideline for the management of patients with atrial fibrillation: a report of the American College of Cardiology/American Heart Association task force on practice guidelines and the heart rhythm society. Circulation. (2014) 130:e199-267. doi: 10.1161/CIR.0000000000000041

37. Lip GYH, Banerjee A, Boriani G, Chiang C, Fargo R, Freedman B, et al. Antithrombotic therapy for atrial fibrillation. Chest. (2018) 154:1121-201. doi: $10.1016 /$ j.chest.2018.07.040

38. Lip GYH, Freedman B, De Caterina R, Potpara TS. Stroke prevention in atrial fibrillation: past, present and future. Thromb Haemost. (2017) 117:1230-9. doi: 10.1160/TH16-11-0876

39. Albertsen IE, Rasmussen LH, Overvad TF, Graungaard T, Larsen TB, Lip GY. Risk of stroke or systemic embolism in atrial fibrillation patients treated with warfarin: a systematic review and meta-analysis. Stroke. (2013) 44:1329-36. doi: 10.1161/STROKEAHA.113.000883

40. Hart RG, Pearce LA, Aguilar MI. Meta-analysis: antithrombotic therapy to prevent stroke in patients who have nonvalvular atrial fibrillation. Ann Intern Med. (2007) 146:857-67. doi: 10.7326/0003-4819-146-12-200706190-00007

41. Fumagalli S, Said SAM, Laroche C, Gabbai D, Marchionni N, Boriani G, et al. Age-related differences in presentation, treatment, and outcome of patients with atrial fibrillation in Europe: The EORP-AF general pilot registry (EURObservational Research Programme-Atrial Fibrillation). JACC Clin Electrophysiol. (2015) 1:326-34. doi: 10.1016/j.jacep.2015.02.019

42. Pugh D, Pugh J, Mead GE. Attitudes of physicians regarding anticoagulation for atrial fibrillation: a systematic review. Age Ageing. (2011) 40:675-83. doi: 10.1093/ageing/afr097

43. Mas Dalmau G, Sant Arderiu E, Enfedaque Montes MB, Solà I, Pequeño Saco S, Alonso Coello P. Patients' and physicians' perceptions and attitudes about oral anticoagulation and atrial fibrillation: a qualitative systematic review. BMC Fam Pract. (2017) 18:3. doi: 10.1186/s12875-016-0574-0

44. Edmiston MK, Lewis WR. Bleeding risk scores in atrial fibrillation: helpful or harmful? J Am Heart Assoc. (2018) 7:e010582. doi: 10.1161/JAHA.118.010582

45. Friberg L, Rosenqvist M, Lip GYH. Net clinical benefit of warfarin in patients with atrial fibrillation. Circulation. (2012) 125:2298-307. doi: 10.1161/CIRCULATIONAHA.111.055079

46. Lopez-Lopez JA, Sterne JAC, Thom HHZ, Higgins JPT, Hingorani AD, Okoli GN, et al. Oral anticoagulants for prevention of stroke in atrial fibrillation: systematic review, network meta-analysis, and cost effectiveness analysis. BMJ. (2017) 359:j5058. doi: 10.1136/bmj.j5058

47. Liu X, Huang H, Yu J, Cao G, Feng L, Xu Q, et al. Warfarin compared with aspirin for older Chinese patients with stable coronary heart diseases and atrial fibrillation complications. Int J Clin Pharmacol Ther. (2014) 52:454-9. doi: $10.5414 / \mathrm{CP} 201996$

48. Mant J, Hobbs FDR, Fletcher K, Roalfe A, Fitzmaurice D, Lip GYH, et al. Warfarin versus aspirin for stroke prevention in an elderly community population with atrial fibrillation (the birmingham atrial 
fibrillation treatment of the aged study, BAFTA): a randomised controlled trial. Lancet (London, England). (2007) 370:493-503. doi: 10.1016/S0140-6736(07)61233-1

49. Rash A, Downes T, Portner R, Yeo WW, Morgan N, Channer KS. A randomised controlled trial of warfarin versus aspirin for stroke prevention in octogenarians with atrial fibrillation (WASPO). Age Ageing. (2007) 36:151-6. doi: 10.1093/ageing/afl129

50. Bai Y, Guo SD, Deng H, Shantsila A, Fauchier L, Ma CS, et al. Effectiveness and safety of oral anticoagulants in older patients with atrial fibrillation: a systematic review and meta-regression analysis. Age Ageing. (2018) 47:9-17. doi: 10.1093/ageing/afx103

51. Gage BF, Boechler M, Doggette AL, Fortune G, Flaker GC, Rich MW, et al. Adverse outcomes and predictors of underuse of antithrombotic therapy in medicare beneficiaries with chronic atrial fibrillation. Stroke. (2000) 31:8227. doi: $10.1161 / 01$. STR.31.4.822

52. Burton C, Isles C, Norrie J, Hanson R, Grubb E. The safety and adequacy of antithrombotic therapy for atrial fibrillation: a regional cohort study. $\mathrm{Br} \mathrm{J}$ Gen Pr. (2006) 56:697-702.

53. Fosbol EL, Wang TY, Li S, Piccini JP, Lopes RD, Shah B, et al. Safety and effectiveness of antithrombotic strategies in older adult patients with atrial fibrillation and non-ST elevation myocardial infarction. Am Hear J. (2012) 163:720-8. doi: 10.1016/j.ahj.2012.01.017

54. DeWald TA, Becker RC. The pharmacology of novel oral anticoagulants. $J$ Thromb Thrombolysis. (2014) 37:217-33. doi: 10.1007/s11239-013-0967-z

55. Connolly SJ, Ezekowitz MD, Yusuf S, Eikelboom J, Oldgren J, Parekh A, et al. Dabigatran versus warfarin in patients with atrial fibrillation. N Engl J Med. (2009) 361:1139-51. doi: 10.1056/NEJMoa0905561

56. Patel MR, Mahaffey KW, Garg J, Pan G, Singer DE, Hacke W, et al. Rivaroxaban versus warfarin in nonvalvular atrial fibrillation. $N$ Engl J Med. (2011) 365:883-91. doi: 10.1056/NEJMoa1009638

57. Granger CB, Alexander JH, McMurray JJV, Lopes RD, Hylek EM, Hanna M, et al. Apixaban versus warfarin in patients with atrial fibrillation. $N$ Engl J Med. (2011) 365:981-92. doi: 10.1056/NEJMoa1107039

58. Giugliano RP, Ruff CT, Braunwald E, Murphy SA, Wiviott SD, Halperin JL, et al. Edoxaban versus warfarin in patients with atrial fibrillation. $N$ Engl J Med. (2013) 369:2093-104. doi: 10.1056/NEJMoa1310907

59. Hsu C-C, Hsu P-F, Sung S-H, Tu S-T, Yu B-H, Huang C-J, et al. Is There a preferred stroke prevention strategy for diabetic patients with non-valvular atrial fibrillation? comparing warfarin, dabigatran and rivaroxaban. Thromb Haemost. (2018) 118:072-81. doi: 10.1160/TH17-02-0095

60. Halperin JL, Hankey GJ, Wojdyla DM, Piccini JP, Lokhnygina Y, Patel MR, et al. Efficacy and safety of rivaroxaban compared with warfarin among elderly patients with nonvalvular atrial fibrillation in the Rivaroxaban once daily, oral, direct factor Xa inhibition compared with vitamin K antagonism for prevention of stroke and embolism. Circulation. (2014) 130:138-46. doi: 10.1161/CIRCULATIONAHA.113.005008

61. Halvorsen S, Atar D, Yang H, De Caterina R, Erol C, Garcia D, et al. Efficacy and safety of apixaban compared with warfarin according to age for stroke prevention in atrial fibrillation: observations from the ARISTOTLE trial. Eur Heart J. (2014) 35:1864-72. doi: 10.1093/eurheartj/ehu046

62. Kato ET, Giugliano RP, Ruff CT, Koretsune Y, Yamashita T, Kiss RG, et al. Efficacy and safety of edoxaban in elderly patients with atrial fibrillation in the ENGAGE AF-TIMI 48 trial. J Am Heart Assoc. (2016) 5. doi: 10.1161/JAHA.116.003432

63. Lauw MN, Eikelboom JW, Coppens M, Wallentin L, Yusuf S, Ezekowitz M, et al. Effects of dabigatran according to age in atrial fibrillation. Heart. (2017) 103:1015-23. doi: 10.1136/heartjnl-2016-310358

64. Kim I-S, Kim H-J, Kim T-H, Uhm J-S, Joung B, Lee M-H, et al. Non-vitamin $\mathrm{K}$ antagonist oral anticoagulants have better efficacy and equivalent safety compared to warfarin in elderly patients with atrial fibrillation: a systematic review and meta-analysis. J Cardiol. (2018) 72:10512. doi: $10.1016 /$ j.jjcc.2018.01.015

65. Ruff CT, Giugliano RP, Braunwald E, Hoffman EB, Deenadayalu N, Ezekowitz MD, et al. Comparison of the efficacy and safety of new oral anticoagulants with warfarin in patients with atrial fibrillation: a metaanalysis of randomised trials. Lancet (London, England). (2014) 383:955-62. doi: 10.1016/S0140-6736(13)62343-0

66. Briceno DF, Villablanca P, Cyrille N, Massera D, Bader E, Manheimer $\mathrm{E}$, et al. Left atrial appendage occlusion device and novel oral anticoagulants versus warfarin for stroke prevention in nonvalvular atrial fibrillation. Circ Arrhythmia Electrophysiol. (2015) 8:1057-64. doi: 10.1161/CIRCEP.115.002993

67. Sardar P, Chatterjee S, Chaudhari S, Lip GYH. New oral anticoagulants in elderly adults: evidence from a meta-analysis of randomized trials. $\mathrm{J} \mathrm{Am}$ Geriatr Soc. (2014) 62:857-64. doi: 10.1111/jgs.12799

68. Lega J-C, Bertoletti L, Gremillet C, Chapelle C, Mismetti P, Cucherat M, et al. Consistency of safety and efficacy of new oral anticoagulants across subgroups of patients with atrial fibrillation. Ai X, editor. PLoS ONE. (2014) 9:e91398. doi: 10.1371/journal.pone.0091398

69. Lin L, Lim WS, Zhou HJ, Khoo AL, Tan KT, Chew AP, et al. Clinical and safety outcomes of oral antithrombotics for stroke prevention in atrial fibrillation: a systematic review and network meta-analysis. J Am Med Dir Assoc. (2015) 16:1103 e1-19. doi: 10.1016/j.jamda.2015.09.008

70. Nieuwlaat R, Capucci A, Lip GY, Olsson SB, Prins MH, Nieman FH, et al. Antithrombotic treatment in real-life atrial fibrillation patients: a report from the Euro heart survey on atrial fibrillation. Eur Hear J. (2006) 27:3018-26. doi: 10.1093/eurheartj/ehl015

71. Mazzaglia G, Filippi A, Alacqua M, Cowell W, Shakespeare A, Mantovani LG, et al. A national survey of the management of atrial fibrillation with antithrombotic drugs in Italian primary care. Thromb Haemost. (2010) 103:968-75. doi: 10.1160/TH09-08-0525

72. Zoppellaro G, Granziera S, Bertozzo G, Denas G, Marigo L, Petruzzellis $\mathrm{F}$, et al. Consequences of warfarin suspension after major bleeding in very elderly patients with non valvular atrial fibrillation. Thromb Haemost. (2017) 117:1828-30. doi: 10.1160/TH16-11-0846

73. Rivera-Caravaca JM, Roldán V, Esteve-Pastor MA, Valdés M, Vicente V, Lip GYH, et al. Cessation of oral anticoagulation is an important risk factor for stroke and mortality in atrial fibrillation patients. Thromb Haemost. (2017) 117:1448-54. doi: 10.1160/TH16-12-0961

74. Lip GY, Frison L, Halperin JL, Lane DA. Comparative validation of a novel risk score for predicting bleeding risk in anticoagulated patients with atrial fibrillation: the HAS-BLED (hypertension, abnormal renal/liver function, stroke, bleeding history or predisposition, labile INR, elderly, drug. J Am Coll Cardiol. (2011) 57:173-80. doi: 10.1016/j.jacc.2010.09.024

75. Segal JB, McNamara RL, Miller MR, Kim N, Goodman SN, Powe NR, et al. Prevention of thromboembolism in atrial fibrillation. a meta-analysis of trials of anticoagulants and antiplatelet drugs. J Gen Intern Med. (2000) 15:56-67. doi: 10.1046/j.1525-1497.2000.04329.x

76. Lip GY, Edwards SJ. Stroke prevention with aspirin, warfarin and ximelagatran in patients with non-valvular atrial fibrillation: a systematic review and meta-analysis. Thromb Res. (2006) 118:321-33. doi: 10.1016/j.thromres.2005.08.007

77. Andersen LV, Vestergaard P, Deichgraeber P, Lindholt JS, Mortensen LS, Frost L. Warfarin for the prevention of systemic embolism in patients with non-valvular atrial fibrillation: a meta-analysis. Heart. (2008) 94:1607-13. doi: 10.1136/hrt.2007.135657

78. Assiri A, Al-Majzoub O, Kanaan AO, Donovan JL, Silva M. Mixed treatment comparison meta-analysis of aspirin, warfarin, and new anticoagulants for stroke prevention in patients with nonvalvular atrial fibrillation. Clin Ther. (2013) 35:967-984 e2. doi: 10.1016/j.clinthera.2013.05.011

79. Dogliotti A, Paolasso E, Giugliano RP. Current and new oral antithrombotics in non-valvular atrial fibrillation: a network meta-analysis of 79808 patients. Heart. (2014) 100:396-405. doi: 10.1136/heartjnl-2013-304347

80. Aguilar MI, Hart R. Oral anticoagulants for preventing stroke in patients with non-valvular atrial fibrillation and no previous history of stroke or transient ischemic attacks. Cochrane Database Syst Rev. (2005) CD001927. doi: 10.1002/14651858.CD001927.pub2

81. Cooper NJ, Sutton AJ, Lu G, Khunti K. Mixed comparison of stroke prevention treatments in individuals with nonrheumatic atrial fibrillation. Arch Intern Med. (2006) 166:1269-75. doi: 10.1001/archinte.166.12.1269

82. Chao T-F, Liu C-J, Lin Y-J, Chang S-L, Lo L-W, Hu Y-F, et al. Oral anticoagulation in very elderly patients with atrial fibrillation. Circulation. (2018) 138:37-47. doi: 10.1161/CIRCULATIONAHA.117.031658

83. Alnsasra H, Haim M, Senderey AB, Reges O, Leventer-Roberts M, Arnson Y, et al. net clinical benefit of anticoagulant treatments in elderly patients with non-valvular atrial fibrillation: experience from the real world. Hear Rhythm. (2018) 16:31-7. doi: 10.1016/j.hrthm.2018.08.016

84. Fawzy AM, Lip GYH. Anticoagulation in elderly patients with nonvalvular atrial fibrillation: a balancing act. Hear Rhythm. (2019) 16:38-40. doi: 10.1016/j.hrthm.2018.09.011 
85. Desai NR, Krumme AA, Schneeweiss S, Shrank WH, Brill G, Pezalla EJ, et al. Patterns of initiation of oral anticoagulants in patients with atrial fibrillation- quality and cost implications. Am J Med. (2014) 127:10751082.e1. doi: 10.1016/j.amjmed.2014.05.013

86. Staerk L, Fosbøl EL, Gadsbøll K, Sindet-Pedersen C, Pallisgaard JL, Lamberts $\mathrm{M}$, et al. Non-vitamin $\mathrm{K}$ antagonist oral anticoagulation usage according to age among patients with atrial fibrillation: temporal trends 2011-2015 in Denmark. Sci Rep. (2016) 6:31477. doi: 10.1038/srep31477

87. Sharma M, Cornelius VR, Patel JP, Davies JG, Molokhia M. Efficacy and harms of direct oral anticoagulants in the elderly for stroke prevention in atrial fibrillation and secondary prevention of venous thromboembolism: systematic review and meta-analysis. Circulation. (2015) 132:194-204. doi: 10.1161/CIRCULATIONAHA.114.013267

88. Romanelli RJ, Nolting L, Dolginsky M, Kym E, Orrico KB. Dabigatran versus warfarin for atrial fibrillation in real-world clinical practice: a systematic review and meta-analysis. Circ Cardiovasc Qual Outcomes. (2016) 9:126-34. doi: 10.1161/CIRCOUTCOMES.115.002369

89. Ng KH, Shestakovska O, Connolly SJ, Eikelboom JW, Avezum A, Diaz R, et al. Efficacy and safety of apixaban compared with aspirin in the elderly: a subgroup analysis from the AVERROES trial. Age Ageing. (2016) 45:77-83. doi: 10.1093/ageing/afv156

90. Devereaux PJ, Anderson DR, Gardner MJ, Putnam W, Flowerdew GJ, Brownell BF, et al. Differences between perspectives of physicians and patients on anticoagulation in patients with atrial fibrillation: observational study. BMJ. (2001) 323:1218-22. doi: 10.1136/bmj.323.7323.1218

91. Xue Q-L. The frailty syndrome: definition and natural history. Clin Geriatr Med. (2011) 27:1-15. doi: 10.1016/j.cger.2010.08.009

92. Theou O, Sluggett JK, Bell JS, Lalic S, Cooper T, Robson L, et al. Frailty, hospitalization, and mortality in residential aged care. J Gerontol A Biol Sci Med Sci. (2018) 73:1090-6. doi: 10.1093/gerona/glx185

93. Villani ER, Tummolo AM, Palmer K, Gravina EM, Vetrano DL, Bernabei R, et al. Frailty and atrial fibrillation: a systematic review. Eur J Intern Med. (2018) 56:33-8. doi: 10.1016/j.ejim.2018.04.018

94. Heckman GA, Braceland B. Integrating frailty assessment into cardiovascular decision making. Can J Cardiol. (2016) 32:139-41. doi: 10.1016/j.cjca.2015.06.011

95. Clegg A, Young J, Iliffe S, Rikkert MO, Rockwood K. Frailty in elderly people. Lancet. (2013) 381:752-62. doi: 10.1016/S0140-6736(12)62167-9

96. Ng TP, Feng L, Nyunt MSZ, Larbi A, Yap KB. Frailty in older persons: multisystem risk factors and the frailty risk index (FRI). J Am Med Dir Assoc. (2014) 15:635-42. doi: 10.1016/j.jamda.2014.03.008

97. Wilkinson C, Todd O, Clegg A, Gale CP, Hall M. Management of atrial fibrillation for older people with frailty: a systematic review and metaanalysis. Age Ageing. (2019) 48:196-203. doi: 10.1093/ageing/afy180

98. Song X, Mitnitski A, Rockwood K. Prevalence and 10-year outcomes of frailty in older adults in relation to deficit accumulation. J Am Geriatr Soc. (2010) 58:681-7. doi: 10.1111/j.1532-5415.2010.02764.x

99. Rockwood K, Song X, MacKnight C, Bergman H, Hogan DB, McDowell I, et al. A global clinical measure of fitness and frailty in elderly people. CMAJ. (2005) 173:489-95. doi: 10.1503/cmaj.050051

100. Rolfson DB, Majumdar SR, Tsuyuki RT, Tahir A, Rockwood K. Validity and reliability of the edmonton frail scale. Age Ageing. (2006) 35:526-9. doi: 10.1093/ageing/afl041

101. Peters LL, Boter H, Buskens E, Slaets JPJ. Measurement properties of the groningen frailty indicator in home-dwelling and institutionalized elderly people. J Am Med Dir Assoc. (2012) 13:546-51. doi: 10.1016/j.jamda.2012.04.007

102. Fried LP, Tangen CM, Walston J, Newman AB, Hirsch C, Gottdiener J, et al. Frailty in older adults: evidence for a phenotype. J Gerontol A Biol Sci Med Sci. (2001) 56:M146-56. doi: 10.1093/gerona/56.3.M146

103. Mitnitski AB, Mogilner AJ, Rockwood K. Accumulation of deficits as a proxy measure of aging. Sci World J. (2001) 1:323-36. doi: 10.1100/tsw.2001.58

104. Rockwood K, Mitnitski A. Frailty in relation to the accumulation of deficits. J Gerontol A Biol Sci Med Sci. (2007) 62:722-7. doi: 10.1093/gerona/ 62.7 .722

105. Cesari M, Gambassi G, Abellan van Kan G, Vellas B. The frailty phenotype and the frailty index: different instruments for different purposes. Age Ageing. (2014) 43:10-2. doi: 10.1093/ageing/aft160
106. Rockwood K, Song X, Mitnitski A. Changes in relative fitness and frailty across the adult lifespan: evidence from the Canadian national population health survey. Can Med Assoc J. (2011) 183:E487-94. doi: $10.1503 / \mathrm{cmaj} .101271$

107. Li G, Thabane L, Ioannidis G, Kennedy C, Papaioannou A, Adachi JD. Comparison between frailty index of deficit accumulation and phenotypic model to predict risk of falls: data from the global longitudinal study of osteoporosis in women (GLOW) Hamilton cohort. PLoS ONE. (2015) 10:e0120144. doi: 10.1371/journal.pone.0120144

108. Parker SG, McCue P, Phelps K, McCleod A, Arora S, Nockels K, et al. What is comprehensive geriatric assessment (CGA)? an umbrella review. Age Ageing. (2018) 47:149-55. doi: 10.1093/ageing/afx166

109. Perera V, Bajorek BV, Matthews S, Hilmer SN. The impact of frailty on the utilisation of antithrombotic therapy in older patients with atrial fibrillation. Age Ageing. (2009) 38:156-62. doi: 10.1093/ageing/afn293

110. Ekerstad N, Karlsson T, Soderqvist S, Karlson BW. Hospitalized frail elderly patients - atrial fibrillation, anticoagulation and 12 months' outcomes. Clin Interv Aging. (2018) 13:749-56. doi: 10.2147/CIA.S159373

111. Oqab Z, Pournazari P, Sheldon RS. What is the impact of frailty on prescription of anticoagulation in elderly patients with atrial fibrillation? a systematic review and meta-analysis. J Atr Fibril. (2018) 10:1870. doi: 10.4022/jafib.1870

112. Cheng $\mathrm{M}-\mathrm{H}$, Chang S-F. Frailty as a risk factor for falls among community dwelling people: evidence from a meta-analysis. J Nurs Scholarsh. (2017) 49:529-36. doi: 10.1111/jnu.12322

113. Cesari M, Landi F, Torre S, Onder G, Lattanzio F, Bernabei R. Prevalence and risk factors for falls in an older community-dwelling population. J Gerontol Ser A Biol Sci Med Sci. (2002) 57:M722-6. doi: 10.1093/gerona/57.11.M722

114. Man-Son-Hing M, Nichol G, Lau A, Laupacis A. Choosing antithrombotic therapy for elderly patients with atrial fibrillation who are at risk for falls. Arch Intern Med. (1999) 159:677-85. doi: 10.1001/archinte.159.7.677

115. Papakonstantinou PE, Asimakopoulou NI, Papadakis JA, Leventis D, Panousieris M, Mentzantonakis G, et al. Frailty status affects the decision for long-term anticoagulation therapy in elderly patients with atrial fibrillation. Drugs Aging. (2018) 35:897-905. doi: 10.1007/s40266-018-0587-6

116. Sanchez-Barba B, Navarrete-Reyes AP, Avila-Funes JA. Are geriatric syndromes associated with reluctance to initiate oral anticoagulation therapy in elderly adults with nonvalvular atrial fibrillation? J Am Geriatr Soc. (2013) 61:2236-7. doi: 10.1111/jgs.12582

117. Maes F, Dalleur O, Henrard S, Wouters D, Scavee C, Spinewine A, et al. Risk scores and geriatric profile: can they really help us in anticoagulation decision making among older patients suffering from atrial fibrillation? Clin Interv Aging. (2014) 9:1091-9. doi: 10.2147/CIA.S62597

118. De Breucker S, Herzog G, Pepersack T. Could geriatric characteristics explain the under-prescription of anticoagulation therapy for older patients admitted with atrial fibrillation? a retrospective observational study. Drugs Aging. (2010) 27:807-13. doi: 10.2165/11537900-000000000-00000

119. Madhavan M, Holmes DN, Piccini JP, Ansell JE, Fonarow GC, Hylek EM, et al. Association of frailty and cognitive impairment with benefits of oral anticoagulation in patients with atrial fibrillation. Am Heart J. (2019) 211:7789. doi: 10.1016/j.ahj.2019.01.005

120. Lefebvre MC, St-Onge M, Glazer-Cavanagh M, Bell L, Kha Nguyen JN, Viet-Quoc Nguyen P, et al. The effect of bleeding risk and frailty status on anticoagulation patterns in octogenarians with atrial fibrillation: the FRAILAF study. Can J Cardiol. (2016) 32:169-76. doi: 10.1016/j.cjca.2015.05.012

121. Elias MF, Sullivan LM, Elias PK, Vasan RS, D’Agostino Sr. RB, Seshadri S, et al. Atrial fibrillation is associated with lower cognitive performance in the Framingham offspring men. J Stroke Cerebrovasc Dis. (2006) 15:214-22. doi: 10.1016/j.jstrokecerebrovasdis.2006.05.009

122. Bunch TJ, Weiss JP, Crandall BG, May HT, Bair TL, Osborn JS, et al. Atrial fibrillation is independently associated with senile, vascular, and Alzheimer's dementia. Hear Rhythm. (2010) 7:433-7. doi: 10.1016/j.hrthm.2009.12.004

123. Dublin S, Anderson ML, Haneuse SJ, Heckbert SR, Crane PK, Breitner JC, et al. Atrial fibrillation and risk of dementia: a prospective cohort study. $J$ Am Geriatr Soc. (2011) 59:1369-75. doi: 10.1111/j.1532-5415.2011.03508.x

124. Hugo J, Ganguli M. Dementia and cognitive impairment: epidemiology, diagnosis, and treatment. Clin Geriatr Med. (2014) 30:421-42. doi: 10.1016/j.cger.2014.04.001 
125. Marzona I, O’Donnell M, Teo K, Gao P, Anderson C, Bosch J, et al. Increased risk of cognitive and functional decline in patients with atrial fibrillation: results of the ONTARGET and TRANSCEND studies. CMAJ. (2012) 184:E329-36. doi: 10.1503/cmaj.111173

126. van Veluw SJ, Shih AY, Smith EE, Chen C, Schneider JA, Wardlaw $\mathrm{JM}$, et al. Detection, risk factors, and functional consequences of cerebral microinfarcts. Lancet Neurol. (2017) 16:730-40. doi: 10.1016/S1474-4422(17)30196-5

127. Diener H-C, Hart RG, Koudstaal PJ, Lane DA, Lip GYH. Atrial fibrillation and cognitive function. J Am Coll Cardiol. (2019) 73:612-9. doi: 10.1016/j.jacc.2018.10.077

128. Chatap G, Giraud K, Vincent J-P. Atrial fibrillation in the elderly. Drugs Aging. (2002) 19:819-46. doi: 10.2165/00002512-200219110-00002

129. Lavy S, Stern S, Melamed E, Cooper G, Keren A, Levy P. Effect of chronic atrial fibrillation on regional cerebral blood flow. Stroke. (1980) 11:35-8. doi: 10.1161/01.STR.11.1.35

130. Kalantarian S, Stern TA, Mansour M, Ruskin JN. Cognitive impairment associated with atrial fibrillation: a meta-analysis. Ann Intern Med. (2013) 158(5 Pt 1):338-46. doi: 10.7326/0003-4819-158-5-201303050-00007

131. Chen LY, Norby FL, Gottesman RF, Mosley TH, Soliman EZ, Agarwal SK, et al. Association of atrial fibrillation with cognitive decline and dementia over 20 years: the ARIC-NCS (atherosclerosis risk in communities neurocognitive study). J Am Heart Assoc. (2018) 7:e007301. doi: 10.1161/JAHA.117.007301

132. de Bruijn RFAG, Heeringa J, Wolters FJ, Franco OH, Stricker BHC, Hofman A, et al. Association between atrial fibrillation and dementia in the general population. JAMA Neurol. (2015) 72:1288. doi: 10.1001/jamaneurol.2015.2161

133. Cheng W, Liu W, Li B, Li D. Relationship of anticoagulant therapy with cognitive impairment among patients with atrial fibrillation: a metaanalysis and systematic review. J Cardiovasc Pharmacol. (2018) 71:380-7. doi: 10.1097/FJC.0000000000000575

134. Mongkhon P, Naser AY, Fanning L, Tse G, Lau WCY, Wong ICK, et al. Oral anticoagulants and risk of dementia: a systematic review and meta-analysis of observational studies and randomized controlled trials. Neurosci Biobehav Rev. (2019) 96:1-9. doi: 10.1016/j.neubiorev.2018.10.025

135. Mavaddat N, Roalfe A, Fletcher K, Lip GY, Hobbs FD, Fitzmaurice $\mathrm{D}$, et al. Warfarin versus aspirin for prevention of cognitive decline in atrial fibrillation: randomized controlled trial (birmingham atrial fibrillation treatment of the aged study). Stroke. (2014) 45:1381-6. doi: 10.1161/STROKEAHA.113.004009

136. Moffitt P, Lane DA, Park H, O'Connell J, Quinn TJ. Thromboprophylaxis in atrial fibrillation and association with cognitive decline: systematic review. Age Ageing. (2016) 45:767-75. doi: 10.1093/ageing/afw104

137. Jacobs V, May HT, Bair TL, Crandall BG, Cutler MJ, Day JD, et al. Longterm population-based cerebral ischemic event and cognitive outcomes of direct oral anticoagulants compared with warfarin among long-term anticoagulated patients for atrial fibrillation. Am J Cardiol. (2016) 118:210-4. doi: 10.1016/j.amjcard.2016.04.039

138. Bunch TJ, May HT, Bair TL, Crandall BG, Cutler MJ, Day JD, et al. Atrial fibrillation patients treated with long-term warfarin anticoagulation have higher rates of all dementia types compared with patients receiving longterm warfarin for other indications. J Am Heart Assoc. (2016) 5:e003932. doi: 10.1161/JAHA.116.003932

139. Barber M, Tait RC, Scott J, Rumley A, Lowe GD, Stott DJ. Dementia in subjects with atrial fibrillation: hemostatic function and the role of anticoagulation. J Thromb Haemost. (2004) 2:1873-8. doi: 10.1111/j.1538-7836.2004.00993.x

140. Jankowska-Polanska B, Katarzyna L, Lidia A, Joanna J, Dudek K, Izabella U. Cognitive function and adherence to anticoagulation treatment in patients with atrial fibrillation. J Geriatr Cardiol. (2016) 13:559-65. doi: 10.11909/j.issn.1671-5411.2016.07.006

141. Rodriguez-Bernal CL, Peiro S, Hurtado I, Garcia-Sempere A, SanfelixGimeno G. Primary nonadherence to oral anticoagulants in patients with atrial fibrillation: real-world data from a population-based cohort. J Manag Care Spec Pharm. (2018) 24:440-8. doi: 10.18553/jmcp.201 8.24.5.440
142. Hylek E. Treatment persistence in atrial fibrillation: the next major hurdle. Thromb Haemost. (2018) 118:2018-9. doi: 10.1055/s-0038-1676101

143. Pritchett R, Bem D, Turner G, Thomas G, Clarke J, Fellows R, et al. Improving the prescription of oral anticoagulants in atrial fibrillation: a systematic review. Thromb Haemost. (2019) 119:294-307. doi: 10.1055/s-0038-1676835

144. Jacobs V, Graves KG, Bunch TJ. Anticoagulant use in atrial fibrillation and risk of dementia: review of contemporary knowledge. Expert Rev Cardiovasc Ther. (2017) 15:897-903. doi: 10.1080/14779072.2017.1411189

145. Shariff N, Desai RV, Patel K, Ahmed MI, Fonarow GC, Rich MW, et al. Rate-control versus rhythm-control strategies and outcomes in septuagenarians with atrial fibrillation. Am J Med. (2013) 126:887-93. doi: 10.1016/j.amjmed.2013.04.021

146. Paciullo F, Proietti M, Bianconi V, Nobili A, Pirro M, Mannucci PM, et al. Choice and outcomes of rate control versus rhythm control in elderly patients with atrial fibrillation: a report from the REPOSI study. Drugs Aging. (2018) 35:365-73. doi: 10.1007/s40266-018-0532-8

147. Perez A, Touchette DR, DiDomenico RJ, Stamos TD, Walton SM. Comparison of rate control versus rhythm control for management of atrial fibrillation in patients with coexisting heart failure: a cost-effectiveness analysis. Pharmacotherapy. (2011) 31:552-65. doi: 10.1592/phco.31.6.552

148. Tsadok MA, Jackevicius CA, Essebag V, Eisenberg MJ, Rahme E, Humphries $\mathrm{KH}$, et al. Rhythm versus rate control therapy and subsequent stroke or transient ischemic attack in patients with atrial fibrillation. Circulation. (2012) 126:2680-7. doi: 10.1161/CIRCULATIONAHA.112.092494

149. Ha AC, Breithardt G, Camm AJ, Crijns HJ, Fitzmaurice GM, Kowey PR, et al. Health-related quality of life in patients with atrial fibrillation treated with rhythm control versus rate control: insights from a prospective international registry (registry on cardiac rhythm disorders assessing the control of atrial fibrillation: REC. Circ Cardiovasc Qual Outcomes. (2014) 7:896-904. doi: 10.1161/HCQ.0000000000000011

150. Proietti M, Mujovic N, Potpara T. Optimizing stroke and bleeding risk assessment in patients with atrial fibrillation: a balance of evidence, practicality and precision. Thromb Haemost. (2018) 118:2014-7. doi: 10.1055/s-0038-1676074

151. Lip GYH. The ABC pathway: an integrated approach to improve AF management. Nat Rev Cardiol. (2017) 14:627-8. doi: $10.1038 /$ nrcardio.2017.153

152. Pastori D, Farcomeni A, Pignatelli P, Violi F, Lip GY. ABC (atrial fibrillation better care) pathway and healthcare costs in atrial fibrillation: The ATHEROAF study. Am J Med. (2019) doi: 10.1016/j.amjmed.2019.01.003. [Epub ahead of print].

153. Pastori D, Pignatelli P, Menichelli D, Violi F, Lip GYH. Integrated care management of patients with atrial fibrillation and risk of cardiovascular events. Mayo Clin Proc. (2018) 94:1261-7. doi: 10.1016/j.mayocp.2018.10.022

154. Proietti M, Romiti GF, Olshansky B, Lane DA, Lip GYH. Improved outcomes by integrated care of anticoagulated patients with atrial fibrillation using the simple ABC (atrial fibrillation better care) pathway. Am J Med. (2018) 131:1359-66.e6. doi: 10.1016/j.amjmed.2018.06.012

Conflict of Interest Statement: GL Consultant for Bayer/Janssen, BMS/Pfizer, Medtronic, Boehringer Ingelheim, Novartis, Verseon, and Daiichi-Sankyo. Speaker for Bayer, BMS/Pfizer, Medtronic, Boehringer Ingelheim, and DaiichiSankyo.

The remaining authors declare that the research was conducted in the absence of any commercial or financial relationships that could be construed as a potential conflict of interest.

Copyright (c) 2019 Zathar, Karunatilleke, Fawzy and Lip. This is an open-access article distributed under the terms of the Creative Commons Attribution License (CC $B Y)$. The use, distribution or reproduction in other forums is permitted, provided the original author(s) and the copyright owner(s) are credited and that the original publication in this journal is cited, in accordance with accepted academic practice. No use, distribution or reproduction is permitted which does not comply with these terms. 